\title{
Hyperglycemia and Endothelial Dysfunction in Atherosclerosis: Lessons from Type 1 Diabetes
}

\author{
Steven Daniel Funk, Arif Yurdagul Jr, and A. Wayne Orr \\ Departments of Cell Biology and Anatomy and Pathology, LSU Health Sciences Center, Shreveport, LA 71130, USA
}

Correspondence should be addressed to A. Wayne Orr, aorr@lsuhsc.edu

Received 7 September 2011; Accepted 27 October 2011

Academic Editor: Matthew R. Spite

Copyright (๑) 2012 Steven Daniel Funk et al. This is an open access article distributed under the Creative Commons Attribution License, which permits unrestricted use, distribution, and reproduction in any medium, provided the original work is properly cited.

A clear relationship between diabetes and cardiovascular disease has been established for decades. Despite this, the mechanisms by which diabetes contributes to plaque formation remain in question. Some of this confusion derives from studies in type 2 diabetics where multiple components of metabolic syndrome show proatherosclerotic effects independent of underlying diabetes. However, the hyperglycemia that defines the diabetic condition independently affects atherogenesis in cell culture systems, animal models, and human patients. Endothelial cell biology plays a central role in atherosclerotic plaque formation regulating vessel permeability, inflammation, and thrombosis. The current paper highlights the mechanisms by which hyperglycemia affects endothelial cell biology to promote plaque formation.

\section{Cardiovascular Disease and Diabetes Mellitus}

Treatment of cardiovascular disease (CVD), manifesting in the form of myocardial infarction, stroke, and peripheral artery disease, represents one of biomedical sciences best success stories over the past several decades $[1,2]$. Through clinical trials, epidemiology, and basic science, we have identified a host of risk factors and designed drugs targeting these risk factors that improve patient survival. The cholesterollowering statin family of therapeutics reduces the 5-year risk of cardiovascular-associated mortality by $\sim 25 \%$ in patients with a history of prior CVD [3]. However, statins have not shown similar protection in patients without a prior history of CVD $[4,5]$, and CVD remains the leading cause of death in developed countries $[2,6]$. Furthermore, the current obesity epidemic threatens to worsen the incidence of CVD in the coming years, undoing the progress we have made to this point [7].

More than $80 \%$ of the CVD-associated death and disability is attributed to atherosclerosis, the excessive accumulation of lipids, cholesterol, inflammatory cells, and connective tissue in the vessel wall $[8,9]$. While clinically silent for decades, atherosclerotic plaques can grow to occlude the vessel lumen reducing blood flow to target tissues $[8,9]$. Although this form of vessel occlusion can result in significant discomfort (e.g., angina pectoris), clinical events most often result from thrombus formation due to plaque deterioration or rupture resulting in a rapid cessation in blood flow to target tissue. Theories concerning the pathogenesis of atherosclerosis have changed over the years, maturing concomitantly with our understanding of vascular biology. We now know that atherosclerosis is a chronic inflammatory disease with multiple risk factors, such as hypercholesterolemia, dyslipidemia, diabetes, hypertension, and smoking, all playing roles in propagating the local inflammatory response $[9,10]$.

Mouse models resulting in hypercholesterolemia, such as the ApoE knockout mouse and the low density lipoprotein (LDL) receptor knockout mouse, have allowed us to better understand the pathogenesis of atherosclerotic plaque formation and gain mechanistic insight into various biochemical pathways in mediating this response [11]. Atherosclerotic plaque production in both mice and humans localizes to discrete regions of the vascular tree that experience alterations in blood flow, such as vessel curvatures, branch points, and bifurcations [12]. Coupled with endothelial cell culture 




FIGURE 1: Stages of atherosclerotic plaque formation. Early apoB-containing lipoprotein accumulation and monocyte binding drive the early stages of plaque development forming fatty streaks in the vessel wall. While these processes continue in advanced atherosclerosis, monocyte cell death, smooth muscle recruitment, and matrix deposition are hallmarks of atheroma formation. Superficial plaque erosion and rupture of the smooth muscle-rich fibrotic cap cause plaque-associated thrombosis culminating in a clinical event.

models, we now understand that shear stress, the frictional force generated by flowing blood, exerts a protective effect on the vascular endothelium to limit inflammation, thrombosis, and endothelial turnover $[12,13]$. In contrast, turbulent flow promotes endothelial permeability and proinflammatory responses. Increased endothelial permeability and altered intimal matrix protein composition promote deposition of apoB-containing LDL particles within the intimal matrix (Figure 1) $[14,15]$. Oxidation of LDL within the vessel wall enhances its proinflammatory properties resulting in local endothelial cell expression of inflammatory proteins (e.g., intercellular adhesion molecule (ICAM-1), vascular cell adhesion molecule (VCAM-1)) $[8,16]$. Monocytes target to these regions of local inflammation and engulf the lipid deposits forming foam cells (Figure 1). These early plaque precursors, visible histologically as fatty streaks, accumulate smooth muscle cells, necrotic foam cell debris, lipids, and ECM proteins as they transition to advanced atherosclerotic plaques $[8,9]$. While current methods to detect atherosclerosis rely on plaque stenosis, more than $60 \%$ of myocardial infarctions are caused by plaques showing less than $50 \%$ stenosis [17]. Consistent with this, plaque growth alone rarely results in vessel blockage as blood vessels adapt by expanding to maintain lumen size and affected tissues promote new blood vessel growth (termed angiogenesis) to restore blood supply [8]. Rather, cardiovascular events most often result from thrombus formation and acute vessel occlusion following plaque rupture or superficial plaque erosion (Figure 1) [18]. Plaque rupture is hindered by the plaque's fibrotic cap, a smooth muscle cell and extracellular matrix-rich region overlying the thrombotic necrotic core. Local smooth muscle cell apoptosis and enhanced matrix proteolysis by leukocytederived proteases weaken the cap enhancing the likelihood of plaque rupture; this is termed the "vulnerable plaque" $[18,19]$. While plaque rupture accounts for approximately $70 \%$ of all thrombotic CVD events, the remaining 30\% occurs following superficial plaque erosion resulting in the loss of the protective endothelial cell layer and exposure of the highly thrombogenic intimal matrix (Figure 1) $[18,19]$.

1.1. Diabetes Mellitus and CVD. The ancient Greek physician Aretaeus of Cappadocia used the term diabetes to refer to diseases associated with the excess production of urine [20]. The English physician Thomas Willis coined the term diabetes mellitus, literally translated "honey-sweet diabetes," in 1645 in reference to the sweet-tasting urine of one of his patients [20]. Today, the term diabetes mellitus refers to the family of metabolic conditions associated with the loss of normal glucose regulation resulting in hyperglycemia. In 2000, there were 171 million diabetics worldwide comprising $2.8 \%$ of the population; this number is projected to reach 366 million (4.4\% of the population) by 2030 [21]. Type 1 diabetes, also known as insulin-dependent diabetes mellitus (IDDM), typically results from autoimmune destruction of pancreatic islet cells responsible for insulin secretion within the first few decades of life. In contrast, type 2 diabetes, or non-insulindependent diabetes mellitus (NIDDM), involves progressive insulin resistance as target tissues become insensitive to insulin resulting in chronic hyperglycemia and hyperinsulinemia. Chronic hyperglycemia in patients is measured by determining the level of glycated hemoglobin (HbA1c). Since red blood cells have a 3-month life-span, HbAlc values provide an estimation of average blood glucose levels over time [22]. In healthy patients, HbAlc levels range from 4.0 to $5.9 \%$ corresponding to a blood glucose level of 68 to $123 \mathrm{mg} / \mathrm{dL}$. An HbA1c level greater than 6.5\% (140 mg/dL 
blood glucose) is used as a criterion for the diagnosis of diabetes. However, the HbA1c level does not provide any information concerning periodic spikes in hyperglycemia which may be just as harmful as a sustained higher average glucose. As such, continuous blood glucose monitoring systems are becoming more and more common.

Diabetics have a 2- to 4-fold higher risk for cardiovascular events [23], and nearly $80 \%$ of diabetes-associated deaths are caused by CVD [24]. As such, diabetes is regarded as a coronary heart disease risk equivalent, meaning that the risk for CVD is the same as an individual with a previous CVD event [25]. The enhanced CVD risk in diabetic patients is larger for women than men because women generally enjoy a protection from CVD during their reproductive years, and this protection is lost in diabetics [26]. Type 1 and type 2 diabetic patients show a similar atherosclerotic plaque profile with an increase in necrotic core size and a decrease in the fibrotic cap size $[27,28]$. However, type 2 diabetics show enhanced atherosclerotic plaque burden with more distal plaques compared to type 1 diabetics [28]. Consistent with this disparity, type 2 diabetes represents a multifactorial proatherogenic effect involving various aspects of metabolic syndrome, a combination of hyperglycemia, hyperlipidemia, obesity, and hypertension [29]. Obesity, particularly abdominal obesity, results in enhanced expression of systemic circulating proinflammatory cytokines expression and reduced levels of protective factors such as adiponectin [30,31]. Furthermore, obesity is linked with the hyperlipidemia and hypercholesterolemia classically associated with atherosclerotic plaque formation [30,31]. Due to the presence of these confounding factors, the specific role of hyperglycemia on atherosclerotic plaque formation in type 2 diabetics has been difficult to discern.

Despite these complications, considerable data exist linking hyperglycemia alone to accelerated atherosclerosis in type 1 diabetics, where these confounding atherogenic factors are often absent. Children with type 1 diabetes show enhanced carotid intimal-medial thickness (IMT) compared to nondiabetics [32]. Postmortem studies of young patients and children with type 1 diabetes show enhanced fatty streak formation in the absence of dyslipidemia suggesting that hyperglycemia is an independent risk factor for early plaque development $[33,34]$. Animal models of type 1 diabetes include pancreatic $\beta$-cells destruction by the DNA-alkylating mechanism of streptozotocin [35], targeted autoimmune destruction of $\beta$-cells due to transgenic expression of viral proteins (RIP-GP mice) [36], and decreased proinsulin production and processing due to mutations in the insulin 2 gene (Ins2Akita (Mody) mouse) [37]. Diabetes alone in these animals does not appear to be sufficient for significant atherosclerotic progression. However, when coupled with genetic modifications to the LDL-R or ApoE genes to induce a more human lipoprotein profile, diabetic mice show enhanced atherosclerotic plaque production compared to their nondiabetic littermates [38-40]. Hyperglycemia is strongly associated with early fatty streak formation in atherosclerosis-prone mice, while progression to advanced atherosclerotic plaques requires dyslipidemia [41]. However, diabetes in these models is often associated with elevated hypercholesterolemia compared to nondiabetic controls, making it difficult to elucidate whether the observed effects on atherogenesis are due to hyperglycemia specifically.

Clinical trials have both corroborated and complicated the role of hyperglycemia in atherosclerosis. The DECODE trial showed an association between hyperglycemia and impaired glucose tolerance and CVD $[42,43]$. However, studies to elucidate whether tight glycemia control reduces CVD risk have produced mixed results, likely attributed to the timing of the treatment and the inclusion of low CVD risk or high CVD risk patients. The Diabetes Control and Complications Trial (DCCT) examined the effect of tight glycemic control in young type 1 diabetics with low CVD risk. Within the initial time period of the study, the authors demonstrated reduced microvascular complications but only demonstrated an insignificant (41\%) reduction in CVD events [44]. However, the event rate for CVD in this population was very low. In the Epidemiology of Diabetes Interventions and Complications (EDIC) study, a 10-year followup of the DCCT trial, the investigators found a significant $42 \%$ reduction in CVD events [45]. The UK Prospective Diabetes Study (UKPDS) examined the role of tight glycemic control in newly diagnosed type 2 diabetics. Similarly, this group found a nonsignificant reduction in CVD events (16\%) during the course of the trial [46] but a significant reduction in CVD events in a 10-year follow-up study [47]. However, clinical trials examining stringent glycemic control in patients with an already high CVD risk (Action to Control Cardiovascular Risk in Diabetes (ACCORD), Action in diabetes and Vascular disease: Preterax and Diamicron MR controlled evaluation (ADVANCE), Veterans Affairs Diabetes Trial (VADT)) showed no beneficial effect on CVD [48, 49]. Furthermore, the ACCORD trial demonstrated an increase in CVD-associated death in the intensively controlled group $(\mathrm{HbAlc}<6)$; this effect has been attributed to enhanced weight gain, increased insulin injections, and increased incidence of hypoglycemia. These differential responses may result from the timing of glycemic control, as patients in the VADT trial that were within the first 12 years of diagnosis showed a benefit in the intensive treatment arm [50]. Taken together, data from clinical trials suggest that glucose control early following the diagnosis of diabetes confers protection that is often not evident for decades despite the cessation of differential treatment; consistent with the hypothesis that hyperglycemia plays a larger role in plaque initiation than plaque progression.

\section{Endothelial Cell Activation and Dysfunction in Atherosclerosis}

The endothelial cell layer regulates multiple aspects of vascular physiology such as maintaining a semipermeable blood-tissue barrier, coordinating leukocyte trafficking, preventing thrombosis, and altering vascular tone [51]. During inflammatory responses, endothelial cells undergo a phenotypic conversion, termed endothelial cell activation, characterized by enhanced permeability, elevated leukocyte adhesion molecule expression, and reduced antithrombotic properties [52]. Mediators of endothelial cell activation are 


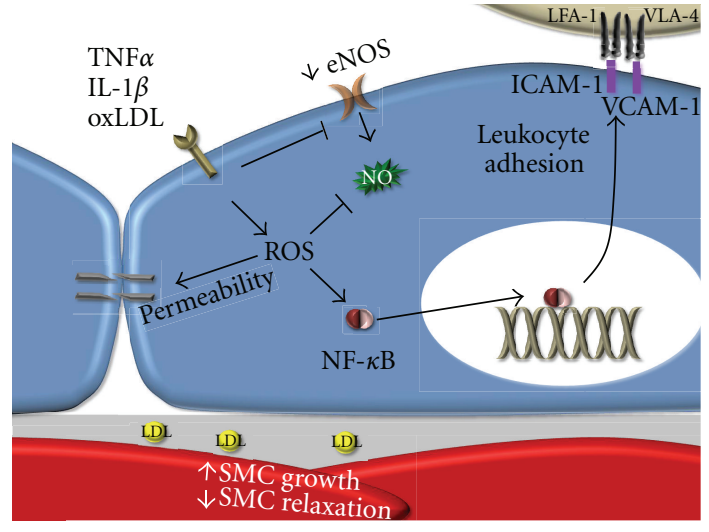

(a)

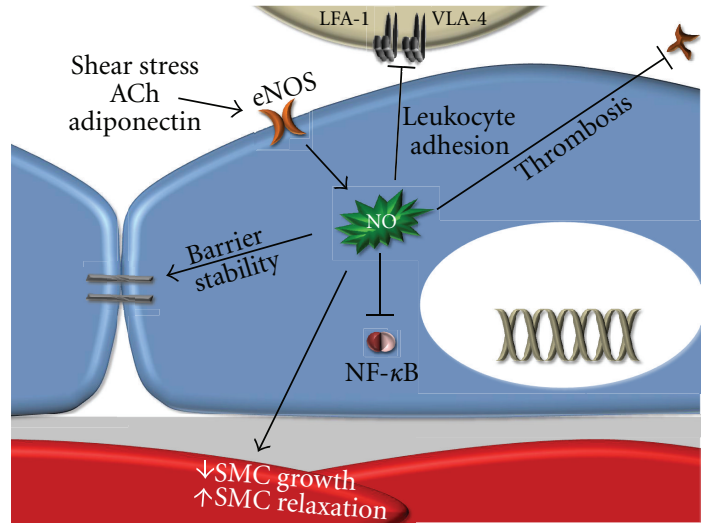

(b)

FIGURE 2: Interplay between endothelial cell dysfunction and endothelial cell activation. (a) Cytokines and oxidized LDL stimulate endothelial cell permeability and NF- $\kappa \mathrm{B}$-dependent inflammatory gene expression. ROS appear to play a central role mediating both responses. (b) In addition to its vasodilatory properties, NO promotes barrier stability, limits inflammation, inhibits platelet aggregation, and limits SMC proliferation. Loss of these protective properties in endothelial cell dysfunction therefore perpetuates endothelial cell activation.

diverse and include proinflammatory cytokines (tumor necrosis factor $\alpha(\mathrm{TNF} \alpha)$, interleukin-1 $\beta$ (IL- $1 \beta))$, bacterial (lipopolysaccharide) and endogenous toxins (oxLDL), vasoconstrictors (angiotensin II, endothelin-1), mechanical forces (shear stress, stretch), and extracellular matrix proteins (fibronectin, fibrinogen) [13, 52-54]. The early rapid phase of endothelial cell activation, termed type 1 activation, involves the remodeling of endothelial cell-cell junctions enhancing monolayer permeability (Figure 2(a)) and the export of Weibel-Palade bodies presenting P-Selectin and $\mathrm{vWF}$ at the endothelial cell surface [52]. Activation of proinflammatory transcription factors such as nuclear factor $\kappa \mathrm{B}(\mathrm{NF}-\kappa \mathrm{B})$ drives the latter phase, termed type $2 \mathrm{ac}-$ tivation, invoking the transcription and expression of proinflammatory genes such as E-selectin, ICAM-1, VCAM-1, chemokines (interleukin-8 (IL-8), monocyte chemotactic protein-1 (MCP-1)), and cytokines (IL-1 $\beta, \mathrm{TNF} \alpha$ ) [52] (Figure 2(a)). The selectin family of cell adhesion molecules induces capture and tethering of leukocytes in the circulation resulting in leukocyte rolling across the endothelium. Rolling provides sufficient reduction in velocity for leukocyte firm adhesion to ICAM-1 and VCAM-1 on the endothelial surface and subsequent transendothelial migration [55]. Presentation of chemokines on the endothelial cell surface activates the leukocyte integrins VLA-4, LFA-1, and Mac-1 increasing their affinity for their ICAM-1/VCAM-1 ligands [55]. Transgenic mice lacking MCP-1, ICAM-1, or the fourth Ig domain of VCAM-1 (VCAM-1 expression is necessary for chorioallantoic fusion, rendering VCAM-1 knockouts lethal) severely limits atherosclerosis [56-60]. These data suggest that atherosclerotic plaque development requires endothelial cell activation involving enhanced expression of proinflammatory adhesion molecules and chemokines.

Endothelial cell dysfunction is defined by a decrease in the bioavailability of nitric oxide (NO), a critical regulator of vascular tone [61]. Multiple stimuli, including shear stress [62], acetylcholine [63], bradykinin [64], insulin [65, 66], and adiponectin [67], activate endothelial cell NO synthase
(eNOS) to convert L-arginine into NO and citrulline. Endothelial cell dysfunction typically occurs when these protective stimuli are diminished, such as at sites of turbulent blood flow (decreased shear stress), in diabetes (decreased insulin signaling), and in obesity (decreased adiponectin). Decreases in eNOS activity and expression, increases in eNOS uncoupling, and direct NO scavenging all mediate endothelial cell dysfunction [61]. eNOS uncoupling appears to be particularly deleterious due to simultaneous decrease in NO production and increased production of the free radical superoxide. Multiple mechanisms have been proposed to mediate eNOS uncoupling, such as diminished bioavailability of L-arginine [68], accumulation of the endogenous eNOS inhibitor asymmetric dimethyl L-arginine (ADMA) [69], oxidation of the critical eNOS cofactor tetrahydrobiopterin $[68,70]$, and direct S-glutathionylation of critical cysteine residues in eNOS [71]. These modifications disrupt electron flow in eNOS causing incomplete catalysis of L-arginine and superoxide production $[72,73]$. Superoxide can react with remaining intracellular NO further reducing cellular NO levels and resulting in the formation of peroxynitrite, a potent oxidant.

Endothelial cell dysfunction is regarded as an early step in atherosclerotic plaque formation primarily due to its effect on endothelial cell activation. Endothelialderived NO reduces integrin activation on platelets $[74,75]$ and leukocytes [76] preventing thrombosis and leukocyte adhesion (Figure 2(b)). NO signaling in the endothelium promotes endothelial barrier integrity [77] and reduces both Weibel-Palade body exocytosis (type 1 activation) [78] and NF- $\kappa \mathrm{B}$-dependent proinflammatory gene expression (type 2 activation) [79, 80] (Figure 2(b)). Turbulent flow, cytokines, and oxLDL reduce eNOS expression and shorten the half-life of eNOS mRNA perpetuating endothelial cell dysfunction and promoting inflammation (Figure 2(b)) [81]. Transgenic mice deficient in eNOS exhibit multiple vascular defects, such as hypertension, enhanced leukocyte rolling and firm adhesion, and vascular remodeling $[82,83]$. Conversely, transgenic 
eNOS overexpression paradoxically enhanced atherosclerotic plaque formation due to eNOS uncoupling and superoxide production; supplementation with critical eNOS cofactor tetrahydrobiopterin reduced this uncoupling and diminished plaque formation in these mice [84]. Subsequent studies with tetrahydrobiopterin supplementation in ApoE mice demonstrated reduced plaque progression suggesting that eNOS uncoupling may be involved in atherosclerotic plaque progression in the absence of eNOS overexpression as well $[85,86]$. Taken together, these data suggest a critical role for endothelial cell dysfunction in the propagation of both endothelial cell activation and atherosclerotic plaque formation.

\section{Hyperglycemia in Endothelial Cell Dysfunction and Activation}

The effect of hyperglycemia on endothelial cells closely mimics that of inflammatory initiators. Endothelial cells exposed to hyperglycemic cell culture media show reduced NO production [87, 88] with enhanced NF- $\kappa$ B activation [89-91], inflammatory gene expression [92-95], and leukocyte recruitment $[93,94,96]$. Transient hyperglycemia causes epigenetic modifications in the promoter of the NF- $\kappa \mathrm{B}$ p65 subunit inducing a sustained increase in NF- $\kappa \mathrm{B}$ expression and NF- $\kappa$ B-dependent VCAM- 1 and MCP- 1 expression for 6 days after restoration of normoglycemia [97], a phenomena termed epigenetic memory. Animal models and studies on human patients have similarly demonstrated an association between hyperglycemia and endothelial cell dysfunction and activation. However, it should be noted that most cell culture systems and animal models tend to utilize glucose levels (20-25 mM; 360 to $450 \mathrm{mg} / \mathrm{dL}$ ) above that seen in diabetic humans (typically 7.8 to $10 \mathrm{mM} ; 140-180 \mathrm{mg} / \mathrm{dL}$ ) to accelerate the occurrence of diabetic complications, and care must be taken when extrapolating results from these experimental systems to the human disease. In the subsequent sections, we will describe the roles of reactive oxygen species, advanced glycation end products (AGEs), metabolic pathway flux, and protein kinase $\mathrm{C}$ signaling in mediating the effects of hyperglycemia-induced endothelial cell dysfunction and activation.

3.1. Reactive Oxygen Species (ROS). Multiple atherogenic stimuli promote endothelial cell dysfunction and activation through enhanced production of ROS. Several ROS play important roles in endothelial pathophysiology including the free radicals superoxide $\left(\mathrm{O}_{2}^{\cdot-}\right)$ and the hydroxyl radical $\left(\mathrm{OH}^{\bullet}\right)$ as well as the non-free radical species hydrogen peroxide $\left(\mathrm{H}_{2} \mathrm{O}_{2}\right)$, peroxynitrite $(\mathrm{ONOO}-/ \mathrm{ONOOH})$, and hypochlorous acid ( $\mathrm{HClO})$ [98]. Turbulent flow [99, 100], atherogenic cytokines (TNF $\alpha$, IL-1 $\beta$ ) [101, 102], vasoconstrictors (angiotensin II) [103] and oxidized LDL [104] all induce ROS-dependent NF- $\kappa \mathrm{B}$ activation to drive endothelial cell expression of proinflammatory and prothrombotic genes $[105,106]$. In addition to inflammatory gene expression, ROS reduce endothelial barrier function [107, 108] contributing to lipoprotein deposition and subsequent oxidative modification of LDL particles in the vessel wall
[98, 109]. Furthermore, ROS stimulates endothelial cell dysfunction by scavenging NO directly or by oxidative modification of tetrahydrobiopterin resulting in eNOS uncoupling [110]. Thus, ROS reduce endothelial cell NO production (scavenging, eNOS uncoupling) while activating both direct (NF- $\kappa \mathrm{B}$ activation) and indirect mediators (LDL oxidation) of endothelial cell activation.

Hyperglycemia stimulates cellular ROS production by four major sources including direct glucose autooxidation [111], mitochondrial superoxide production [112], eNOS uncoupling [113], and AGE-dependent NADPH oxidase activation (Figure 3(a)) [72, 73]. Glucose autooxidation and mitochondrial superoxide are likely to be the initial contributors to ROS-mediated dysfunction elicited by hyperglycemia [72]. Trace amounts of free metals catalyze glucose autooxidation resulting in systemic oxidant stress [114]. Glucose oxidation during glycolysis produces ROS that are generally held in check by the cell's antioxidant defenses, including superoxide dismutase (SOD), thioredoxin, glutathione peroxidase (GP), and catalase [115]. However, these systems become overloaded during hyperglycemia. Whereas many cells downregulate glucose transporters (GLUTs) in response to hyperglycemia, endothelial cells retain expression of noninsulin-dependent GLUTs allowing intracellular glucose to rise concomitantly with extracellular glucose concentrations (Figure 3(a)) [116]. Enhanced glycolytic oxidation and the disruption of the mitochondrial electron transport chain promoting electron shuttling into molecular oxygen stimulates oxidant stress. eNOS uncoupling in response to ROS production further perpetuates oxidant stress under hyperglycemic conditions (Figure 3(b)) [117]. During chronic hyperglycemia, AGE production contributes to ROS production through receptor-mediated NADPH oxidase activation (Figure 3(b)). It should be noted however, that ROS production through distinct cellular sources (NADPH oxidase, mitochondria) can lead to ROS production at secondary sites $[72,118]$, and the relative contributions of each source are likely to fluctuate with disease state and control (hyperglycemic spikes versus AGEs).

Multiple studies have found that preventing ROS production or enhancing the cell's antioxidant systems limits the capacity of hyperglycemia to promote endothelial dysfunction and activation. Inhibiting mitochondrial superoxide production prevents hyperglycemia-induced ROS production, AGE accumulation, and PKC activation suggesting this pathway plays a central role in hyperglycemiainduced endothelial cell responses [119]. Addition of the antioxidant $\mathrm{N}$-acetyl-L-cysteine prevented hyperglycemiaassociated endothelial cell apoptosis [120], whereas the antioxidant coenzyme Q10 inhibits high-glucose-induced proinflammatory gene expression and monocyte binding [121]. Reducing hyperglycemia-induced ROS production using a mitochondrial complex II inhibitor (thenoyltrifluoroacetone (TTFA)) or a Mn SOD mimetic (Mn(III)tetrakis(4-benzoic acid) porphyrin chloride (MnTBAP)) abrogates inflammatory gene expression $[122,123]$ and enhances NO production [123]. Taken together, these studies suggest that limiting ROS production reduces hyperglycemia-induced endothelial cell dysfunction and activation. 


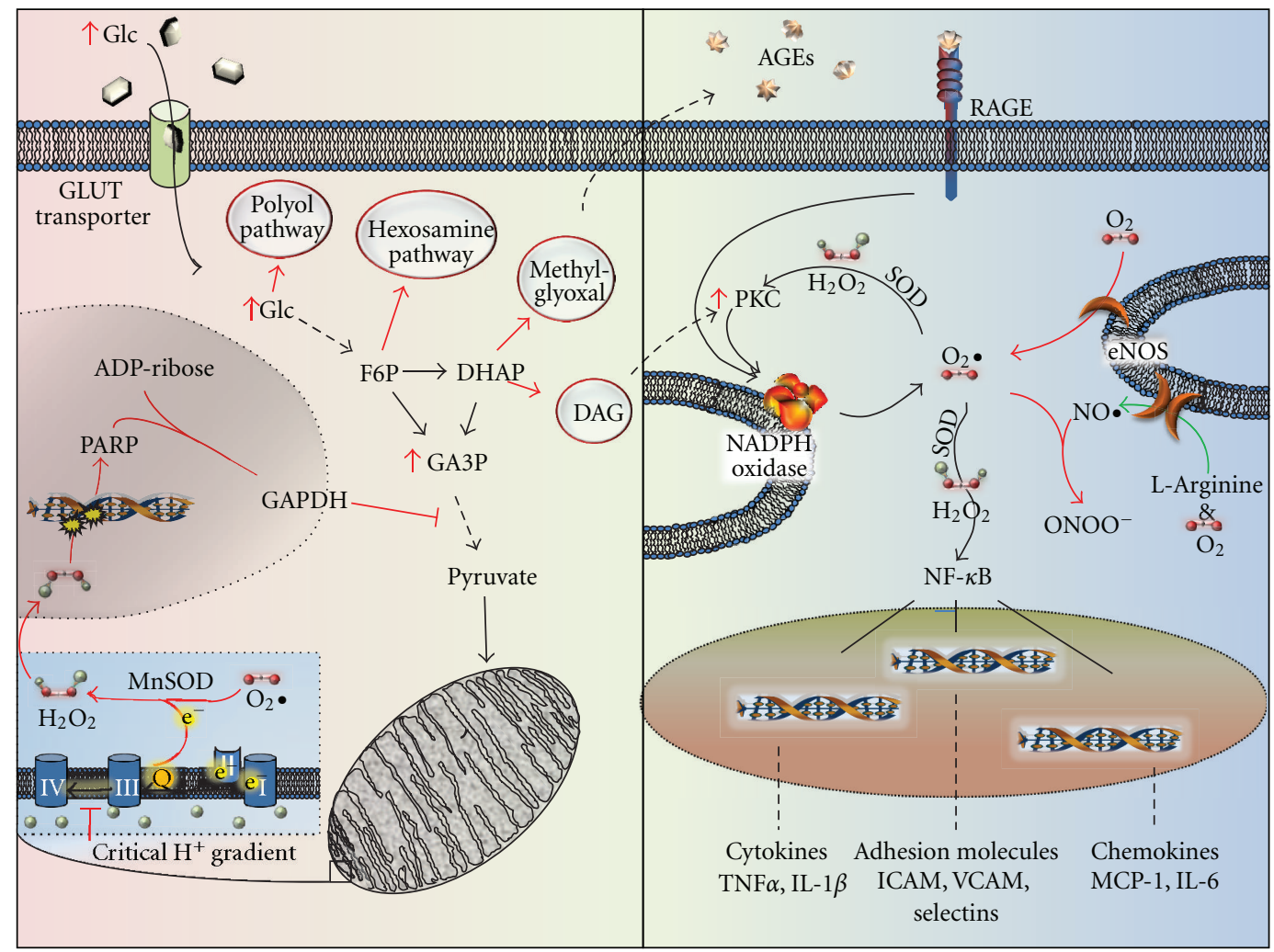

(a)

(b)

FIGURE 3: Hyperglycemia-induced endothelial dysfunction and activation. (a) Hyperglycemia induces metabolic dysfunction through mitochondrial production of superoxide, resulting in PARP activation and subsequent altered glycolytic flux to enhance diacylglycerol production (DAG), methylglyoxal production, and hexosamine and polyol pathway activity. (b) Hyperglycemia-induced oxidative stress is further enhanced by metabolic overproduction of DAG and decreases in $\mathrm{NADH}^{+} /$reduced glutathione (GSH), as well as stimulation of the RAGE receptor. Oxidative stress reduces protective mediators (NO bioavailability) and enhances inflammatory transcription factor (NF- $\kappa \mathrm{B}$ ) activation resulting in inflammatory gene expression and leukocyte recruitment.

Consistent with cell culture models, mouse models of type 1 diabetes show enhanced endothelial oxidative stress, inflammatory gene expression, and leukocyte recruitment [124-126]. Pharmacological and genetic modifications of antioxidant pathways support a role for oxidative stress in hyperglycemia-associated endothelial cell dysfunction and activation. Rings of rabbit aorta treated for 6 hours in hyperglycemic media show reduced ACh-mediated vasodilation compared to normoglycemic controls, and multiple antioxidants (superoxide dismutase, catalase, deferoxamine, or allopurinol) were sufficient to reverse hyperglycemiaassociated impairment in vasodilation [127]. Similarly, multiple antioxidants restored vasodilation in aortic rings isolated from diabetic rats [128, 129]. Diabetic ApoE/glutathione peroxidase- 1 double $\mathrm{KO}$ mice show enhanced atherosclerosis compared to diabetic mice deficient in ApoE alone associated with enhanced VCAM-1 expression and macrophage recruitment [130]. Conversely, the GP-1 mimetic ebselen reduces endothelial dysfunction, proinflammatory gene expression, and atherosclerotic plaque formation in diabetic mice [131, 132]. Antioxidant treatments also reduce endothelial permeability resulting from hyperglycemia $[133,134]$. Taken together, these data provide strong evidence that antioxidants protect endothelial cells from hyperglycemia-induced endothelial cell dysfunction and activation.

Although many antioxidant therapies targeting multiple sources of ROS in experimental models have shown promise, several clinical trials utilizing antioxidants appear to confer no significant protection $[73,135]$. In the Heart Outcomes Prevention Evaluation (HOPE) trial, 3654 diabetic patients receiving supplementation with vitamin $\mathrm{E}$ or placebo for 4.5 years failed to show any cardiovascular benefit for vitamin E [136]. Similarly, the Secondary Prevention with Antioxidants of Cardiovascular Disease in End Stage Renal Disease (SPACE) trial [137], Study to Evaluate Carotid Ultrasound Changes in Patients Treated with Ramipril and Vitamin E (SECURE) trial [138], and the Primary Prevention Project (PPP) trial [139] all failed to show beneficial effects of antioxidants in diabetes-associated cardiovascular disease. However, the lack of a clinical benefit in these trials does not disprove the role of ROS in CVD as there are several reasons why these studies may have failed including uncertain dose requirements for vitamin $\mathrm{E}$, short time frame of clinical trials, and the use of high risk patients with advanced CVD [140]. 
3.2. AGE/RAGE. Another major mechanism of diabetesassociated endothelial cell dysfunction and activation involves hyperglycemia-associated formation of AGEs. Glycation involves the nonenzymatic addition of a carbohydrate moiety onto proteins; this should not be confused with glycosylation that takes place in the ER and Golgi resulting in protein maturation. The nonreversible formation of AGEs results from several reversible reactions, collectively termed the Maillard reaction. First, a reducing sugar, such as glucose or fructose, attaches to the $\alpha$-amino group of either the amino terminus of proteins or lysine residues via nucleophilic attack: the product is known as a Schiff base [141]. This can undergo an Amadori rearrangement forming ketoamines. From here, these ketoamines, synonymously termed Amadori products, take one of two pathways: an oxidative or nonoxidative pathway forming irreversible AGE modifications [142, 143]. Hyperglycemia causes excessive glycation of proteins found in serum (e.g., albumin, hemoglobin, and LDL) and in the vessel wall (e.g., collagen, fibronectin). However, AGE formation by intracellular glycolysis-derived dicarbonyl precursors (glyoxal, methylglyoxal, and 3-deoxyglucosone) occurs at a rate several orders of magnitude higher than nonenzymatic glycation, suggesting that these intermediates may be primarily responsible for both intracellular and extracellular AGE production (Figure 3(b) ) [144, 145]. Glyoxal arises from glucose autooxidation, whereas methylglyoxal formation occurs in response to glyceraldehyde-3-phosphate and dihydroxyacetone phosphate fragmentation [146-148]. While enhanced during hyperglycemia, AGE formation is a naturally occurring process with endogenous negative regulators (ex. glyoxalase I) that degrade the AGE-inducing dicarbonyl intermediates [146]. Interestingly, AGE accumulation during normal aging occurs concomitant with a decrease in glyoxalase I expression [149], and glyoxalase I expression is associated with enhanced lifespan of Caenorhabditis elegans [150].

AGEs carry a large arsenal of weaponry with which to exacerbate diseases, including both receptor-mediated and receptor-independent effects. AGEs bind to multiple cell surface receptors including the "receptor for AGE" (RAGE) [151], AGE receptor 1 (AGER1), AGER3, and CD36 [152]. A member of the immunoglobulin superfamily, RAGE regulates AGE-associated endothelial cell dysfunction and activation. While RAGE receptor signaling is not well understood, RAGE ligation stimulates endothelial ROS production [153], and the NADPH oxidase inhibitor diphenyliodonium (DPI) significantly blunts this induction (Figure 3(b)) [154]. AGE-dependent proinflammatory gene expression (VCAM1, E-selectin) in endothelial cells similarly requires the RAGE receptor [155] and NADPH oxidase activation [154, 156]. In addition to ROS-mediated NO scavenging, AGEs decrease eNOS expression and L-citrulline production (readout of NO production) in endothelial cells [157], and AGEs inhibit histamine-induced NO production in endothelial cells associated with reductions in eNOS serine phosphorylation [158]. Consistent with this, Gao and collaborators show that the impaired vasodilation in blood vessels of diabetic mice is endothelium dependent and RAGE sensitive [159].
In contrast to the proinflammatory RAGE receptor, the alternative AGE receptors AGER1, AGER3, and CD36 stimulate AGE degradation [152], with AGER1 suppressing AGEinduced ROS production [160]. This disparity suggests that AGE-associated inflammation can be regulated at the level of receptor expression. Activation of NO-associated PKG signaling in endothelial cells by treatment with the PDE5 inhibitor Vardenafil reduces RAGE gene expression, suggesting that healthy levels of NO/PKG signaling suppress the AGE/RAGE insult [161]. In contrast, hyperglycemia-induced ROS production promote RAGE expression [162], suggesting a synergistic effect between hyperglycemia-associated glycolytic oxidant stress and AGE/RAGE-dependent oxidant stress.

Receptor-independent effects of AGEs include extracellular matrix modification [163], NO scavenging [164], and glycation of both signaling proteins [165] and LDL [166]. Since AGE formation is irreversible and turnover of ECM is slow, hyperglycemia stimulates considerable glycation of extracellular matrix proteins resulting in vessel stiffening through crosslinking type I collagen and elastin [167-169]. Vessel stiffening contributes to systemic hypertension and increases the strain on the vessel wall [170]. AGE-dependent NO scavenging perpetuates stiffening by enhancing smooth muscle proliferation and increased contractility $[164,171]$. Endothelial cell interactions with subendothelial basement membrane proteins initiate signaling pathways that reduced endothelial cell activation $[100,172]$. Glycation of the subendothelial matrix proteins laminin and collagen IV disrupts matrix self-assembly and prevents endothelial cell adhesion and spreading $[169,173,174]$. Therefore, disrupted interaction with the basement membrane may limit its protective properties while enhancing endothelial cell loss (superficial plaque erosion). In addition to matrix modifications, glycation of intracellular signaling proteins by methylglyoxal activates the endothelial cell stress response (JNK, p38) [175]. However, methylglyoxal inhibits NF- $\kappa \mathrm{B}$ activation by modification of Cys38 blocking DNA binding [165], and JNK signaling in the absence of NF- $\kappa \mathrm{B}$ can promote apoptosis [176]. Consistent with this, methylglyoxal stimulates endothelial cell apoptosis although the signaling mechanisms employed have not been addressed directly [177]. Lastly, glycation of LDL may be as deleterious as LDL oxidation in promoting endothelial cell activation [178]. Glycated LDL binds to the RAGE receptor stimulating endothelial cell dysfunction through calpain-dependent eNOS degradation and promoting inflammatory gene expression through NADPH oxidase-dependent ROS production [179-182].

Several lines of evidence suggest that AGE formation mediates hyperglycemia-associated cardiovascular disease. Pharmacological inhibitors of AGE formation (alagebrium chloride (ALT-711), pyridoxamine dihydrochloride) significantly reduce atherosclerotic plaque formation in diabetic ApoE null mice $[183,184]$. Early clinical trials using ALT711 demonstrated enhanced arterial compliance [185] and improved flow-mediated vasodilation [186] in aged hypertensive patients. Despite these early successes, Alteon (the producer of ALT-711) encountered financial hardship and 
halted drug development. Overexpression of methylglyoxaldegrading enzyme glyoxalase I reduces AGE production and oxidant stress in diabetic rats [187]. Furthermore, polymorphisms in glyoxalase I are associated with carotid atherosclerosis in type 2 diabetics $[188,189]$. A soluble splice variant of RAGE lacking the cytosolic and transmembrane domain scavenges circulating AGEs counteracting their proinflammatory effects. Therapeutic intervention utilizing exogenous sRAGE treatment dose-dependently inhibits leukocyte infiltration, plaque formation, and progression of existing plaques in mouse models $[190,191]$. One caveat to these studies is the interaction of RAGE with oxLDL, suggesting sRAGE may reduce atherosclerosis by scavenging oxLDL. However, ApoE/RAGE double knockout mice and ApoE mice expressing endothelial-specific dominant negative RAGE show reductions in both endothelial cell dysfunction and atherosclerotic plaque formation [192], suggesting that RAGE plays an important role in atherosclerotic plaque formation. RAGE antagonists (TTP488) and humanized sRAGE are making their way through early clinical trials for diabetic nephropathy, Alzheimer's disease, and acute lung injury; however no trials for cardiovascular disease are currently underway [193].

3.3. Metabolic Pathway Flux. In addition to uncoupling the electron transport chain, hyperglycemia pushes glucose flux through alternative metabolic pathways, including the polyol and hexosamine pathways (Figure 3(a)). The polyol pathway consists of aldose reductase and sorbitol dehydrogenase, which mediate the conversion of glucose to sorbitol via NADPH oxidation, and sorbitol to fructose via $\mathrm{NAD}^{+}$reduction, respectively. In hyperglycemic conditions, it is suggested that up to $30 \%$ of metabolized glucose fluxes through the polyol pathway [194] versus the $\sim 3 \%$ under normo-glycemic conditions [195]. Hyperglycemia stimulates aldose reductase expression and may affect activation through ROS-dependent S-thiolation, S-nitrosation, and glutathiolation of a critical cysteine residue (Cys298) [196, 197]. Early studies demonstrated that limiting aldose reductase activity in the lens inhibits cataract formation driven by sorbitol accumulation [196, 198-200]; thus aldose reductase was postulated to mediate peripheral hyperglycemic complications. This effect was proposed to be due to osmotic pressure caused by sorbitol accumulation. However, multiple antioxidants were later found to limit cataract formation under hyperglycemic conditions without affecting sorbitol accumulation suggesting a more complex role for aldose reductase in hyperglycemia-associated diabetic complications [196, 201203].

Aldose reductase is expressed in multiple tissue beds and performs highly context-dependent functions [204]. Inhibiting aldose reductase limits NF- $\kappa$ B activation and proinflammatory gene expression in response to hyperglycemia and proinflammatory cytokines, suggesting aldose reductase plays a proinflammatory function in endothelial cells $[205,206]$. The proinflammatory effect of polyol pathway flux could be explained by the reduction of NADPH and $\mathrm{NAD}^{+}$availability, resulting in reduced production of NO, diminished levels of reduced glutathione, and unbalanced redox stress [72]. However, aldose reductase also catalyzes the reduction of aldehydes produced by lipid peroxidation and glutathiolation [196, 207-209]. Since these aldehydes possess proinflammatory properties, aldose reductase may also function as an antiinflammatory/detoxification mediator [209]. Mouse models of atherogenesis underscore the complexities of aldose reductase activity in the disease setting. Whereas aldose reductase deletion (global) enhances atherosclerotic plaque in the hypercholesterolemic ApoE-null mouse on highfat diet as well as in streptozotocin-induced diabetes [210], general and endothelial targeted overexpression of human AR in models of hypercholesterolemia also showed enhanced plaque size in diabetic animals $[211,212]$. This discrepancy may be due to the significantly reduced levels of aldose reductase in mice, which could limit polyol pathway flux and diminish its potential proinflammatory role [197].

In contrast to the extensive research on the polyol pathway in hyperglycemia, the hexosamine pathway has received considerably less attention, possibly owing to the lack of specific inhibitors $[213,214]$. In the physiological setting, fructose-6-phosphate proceeds from the glycolytic pathway to produce glucosamine-6-phosphate via enzymatic activity of glutamine:fructose-6-phosphate amidotransferase (GFAT). Several intermediate reactions lead to synthesis of UDP-N-acetylglucosamine (GlcNAc), a nucleotide donor utilized in the ER and golgi for glycosylation of various glycoproteins, lipids, and proteoglycans. Additionally, UDPGlcNAc is a substrate of O-GlcNAc transferase (OGT), leading to production of O-linked GlcNAcylated Ser and Thr residues in a wide variety of intracellular proteins $[215,216]$. The regulation of many processes by O-GlcNAc modification has led to the comparison of O-GlcNAcylation to phosphorylation events and redox modification of proteins as a regulator of protein activity, with emphasis on the limited expression of enzymes involved in the regulation of $\mathrm{O}$ GlcNAcylation versus the plethora of cellular kinases mediating phosphorylation events [217].

Protective roles of O-GlcNAcylation have been reported in cardiac ischemia/reperfusion $[218,219]$, and the use of glucosamine to bypass GFAT for UDP-GlcNAc production appears to serve anti-inflammatory roles $[220,221]$. However, protective roles of O-GlcNAcylation may be context dependent. Indeed, hyperglycemia-induced O-GlcNAcylation of eNOS, dependent on the Ser1177 residue, occurs concomitant with decreased Ser1177 phosphorylation and reduced NO production $[88,222]$. Endothelial O-GlcNAcylation is increased in carotid plaques of type II diabetic patients, and inhibition of the hexosamine pathway is sufficient to reverse O-GlcNAcylation-mediated eNOS inhibition in human coronary endothelial cells in hyperglycemic conditions [223]. O-GlcNAcylation stimulates activation of the p38, ERK, and JNK pathways in response to hyperglycemia and contributes to the reduced activation of the insulin receptor and IR substrate, phosphoinositol-3-kinase, and Akt [214, 223]. Additionally, hyperglycemia enhances OGlcNAcylation of the $\mathrm{Sp} 1$ transcription factor regulating expression of the profibrotic growth factor TGF $\beta$ in arterial endothelial cells [224] and smooth muscle cells [225]. 
However, no definitive data exists linking O-GlcNAcylation to enhanced atherosclerotic plaque formation in diabetic mice or human patients.

Despite the discovery and characterization of O-GlcNAcylation in 1986 [226] and OGT in 1990 [216], no mature therapeutics have been developed targeting hexosamine stress. Although the glutamine analogs 6-diazo-5-oxo$\mathrm{L}$-norleucine and azaserine (O-diazoacetyl-L-serine) are frequently used to study the hexosamine pathway by inhibiting GFAT activity, the role of GFAT in glycosylation, and the ubiquitous nature of O-GlcNAcylation make GFAT an unattractive therapeutic target. However, as the regulation and contexts of O-GlcNAcylation are further characterized, new insights may prove this pathway feasible for intervention of hyperglycemic distress. In contrast, several comprehensive reviews highlight the escalating, decades-long success story of aldose reductase inhibitors (ARIs) [227-229]. Although the majority of ARIs to date have been less effective in human patients than in experimental models or have exhibited unforeseen but mild/reversible side effects, the ARIs have consistently demonstrated improvements in peripheral measures including nerve conduction velocity and sensation, albuminurea, and peripheral blood flow. Consequently, pharmaceutical companies have developed increasingly more potent ARIs. Currently, ranirestat is undergoing phase III trials in Europe and the United States, and epalrestat has been used clinically in Japan for several years. While the bulk of these trials and other experimental data support a proinflammatory role for aldose reductase [209], no clinical trials to date have tested the effectiveness of ARIs in treating macrovascular complications of diabetes.

3.4. Protein Kinase C (PKC). The PKC family of serine/ threonine kinases regulates a plethora of cellular functions. Mammalian cells express multiple PKC isoforms divided into subfamilies termed classical PKCs (PKC $\alpha, \mathrm{PKC} \beta \mathrm{I}, \mathrm{PKC} \beta \mathrm{II}$, $\mathrm{PKC} \gamma)$, novel PKCs (PKC $\delta, \mathrm{PKC} \varepsilon, \mathrm{PKC} \eta, \mathrm{PKC} \theta, \mathrm{PKC} \mu)$, and atypical PKCs $(\mathrm{PKC} \zeta, \mathrm{PKC} \lambda / \iota)[230,231]$. Activation mechanisms differ between subclasses with both classical and novel PKC isoforms showing activation by diacylglycerol, phosphatidylserine, and phorbol esters (e.g., phorbol-12myristate-13-acetate (PMA)), whereas only classical PKCs are sensitive to calcium due to the presence of a calcium binding domain in the N-terminus [230, 231]. Atypical PKCs are insensitive to calcium and diacylglycerol and are activated instead by the phosphoinositide 3-kinase (PI-3K)/ phosphoinositide-dependent kinase (PDK1) pathway [230, 231]. Evidence for PKC activation in hyperglycemia has implicated two major pathways leading to PKC activity. First, high-glucose-induced mitochondrial superoxide production leads to poly(ADP-ribose) polymerase (PARP) activation, and subsequent modification and inactivation of GAPDH by ADP-ribose polymers (Figure 3(a)) [72, 232]. GAPDH inactivation results in accumulation of the upstream glycolysis intermediate glyceraldehyde-3 phosphate which can be converted to diacylglycerol promoting the activation of classical and novel PKCs. Second, ligation of the RAGE receptor by AGEs also stimulates PKC activation albeit through uncertain mechanisms (Figure 3(b)) [233].

Signaling through PKC regulates multiple cellular processes involved in endothelial cell dysfunction and activation. PKC phosphorylates eNOS on an inhibitory site (Thr495) blunting eNOS activity [234, 235] and reduces eNOS phosphorylation on the activating Ser1177 site [236, 237]. TNF $\alpha$ reduces eNOS protein stability through PKC $\zeta$ suggesting that $\mathrm{PKC}$ influences $\mathrm{NO}$ production through a variety of mechanisms [238]. Interestingly, a study of the porcine aorta demonstrated that $\mathrm{PKC} \zeta$ showed enhanced activity in regions of disturbed flow prone to atherosclerotic plaque development [239]. Conversely, PKC $\alpha$ shows both positive and negative effects on eNOS activity and NO production depending upon environmental context [240, 241]. In addition to modulating eNOS activity, PKC induces endothelial monolayer permeability directly via phosphorylation of junctional proteins (e.g., occludin) [242, 243] and indirectly through enhanced expression of the permeabilityinducing factors VEGF [244], endothelin-1 [245], and thrombin [246]. Multiple PKC isoforms can feed directly into the NF- $\kappa \mathrm{B}$ activation pathway regulating downstream proinflammatory gene expression $[247,248]$. Classic PKC isoforms PKC $\alpha$ and $\mathrm{PKC} \beta$ mediate NF- $\kappa \mathrm{B}$ activation and expression of ICAM-1/VCAM-1 in response to 12/15-lipoxygenase and apolipoprotein CIII [249, 250]. In contrast, thrombin-induced NF- $\kappa \mathrm{B}$ activation requires the novel isoform $\mathrm{PKC} \delta[251,252]$. The atypical isoform $\mathrm{PKC} \zeta$ mediates TNF $\alpha$-induced NF- $\kappa$ B activation and ICAM expression [253]. Taken together, these data suggest that PKC isoforms play stimulus- and context-dependent roles in modulating endothelial dysfunction and activation.

A mounting body of evidence implicates PKC signaling in multiple modalities of hyperglycemia-induced endothelial cell dysfunction and activation. Hyperglycemia stimulates a PKC-dependent reduction in eNOS expression and NO production in retinal and aortic endothelial cells $[254,255]$. In addition, the PKC activator PMA promotes NADPH oxidase-dependent ROS production, and inhibiting PKC limited high-glucose-induced ROS in endothelial cells suggesting that PKC may reduce NO levels by inducing ROS-dependent scavenging [256]. The general PKC inhibitor staurosporine and the classical PKC inhibitor G06976 reduce hyperglycemia-associated endothelial monolayer permeability suggesting that hyperglycemia-induced PKC signaling promotes endothelial permeability [257, 258]. However, the effect of PKC signaling on endothelial permeability depends upon the isoform involved, as $\mathrm{PKC} \delta$ signaling reduces endothelial permeability in coronary artery endothelial cells and is downregulated in the coronary artery of diabetic rats [259]. Both staurosporine and calphostin, an inhibitor of classic and novel PKC isoforms, block hyperglycemia-induced NF- $\kappa$ B activation $[92,260]$, and a specific PKC $\beta$ inhibitor (ruboxistaurin) prevents AGEs-induced ICAM-1 expression and leukocyte adhesion in HUVECs [261]. Similarly, the PKC $\beta$ inhibitor LY379196 prevents hyperglycemiainduced NF- $\kappa$ B activation [262], VCAM-1 expression [262], and apoptosis [263], suggesting $\mathrm{PKC} \beta$ may be an attractive 
target to limit diabetes-associated endothelial activation in vivo.

Like AGE/RAGE and ROS, PKC appears to regulate endothelial dysfunction/activation and atherosclerotic plaque formation in animal models. PKC $\alpha$ and PKC $\beta$ II show enhanced expression and activation in the diabetic macrovasculature [264-267], and the general PKC inhibitor bisindolylmaleimide-I blunts hyperglycemia-induced leukocyte binding to mesenteric postcapillary venules in vivo [268]. PKC $\beta / A p o E$ double knockout mice develop smaller atherosclerotic plaques than mice deficient in ApoE alone [269], and the PKC $\beta$ inhibitor ruboxistaurin reduces retinal and renal complications in diabetic rats while enhancing ACh-induced aortic vasodilation [270, 271]. In line with these studies, transient hyperglycemia blunts endothelialdependent vasodilation in otherwise healthy human subjects, and PKC $\beta$ inhibition with ruboxistaurin restores normal endothelial function in these patients [272]. Furthermore, ruboxistaurin enhanced brachial artery flow-mediated dilation in type 2 diabetics [273] suggesting that this inhibitor may reduce macrovascular endothelial dysfunction.

\section{Conclusions}

Multiple pathways drive hyperglycemia-induced endothelial cell dysfunction and activation including enhanced glycolysis (ROS), the buildup of glycolytic intermediates (polyol pathway, hexosamine pathway, $\mathrm{PKC}$ activation, and $\mathrm{AGE}$ formation), and AGE-modification of proteins (ROS, PKC). Given the interdependent nature of these pathways, it is not surprising that inhibitors targeting one of these pathways profoundly affect hyperglycemia-induced alterations in endothelial cell function. But which pathways are more attractive targets for clinical intervention? Trials limiting polyol pathway flux, AGE production, and RAGE signaling have shown a significant improvement in endothelial cell function; however these are not being actively pursued to treat CVD. The PKC $\beta$ inhibitor ruboxistaurin shows great promise to reduce microvascular complications of diabetes and early results suggest an improvement in endothelial cell function in CVD patients. However, no trials to date have examined the effects of ruboxistaurin on diabetes-associated atherosclerotic burden directly. Prevention of early ROS production using mitochondrial complex II inhibitors blocks downstream AGE production and protects endothelial cells from transitioning to the dysfunctional or activated phenotypes [119]. However, clinical trials to target these early ROSdependent pathways have shown less promising results than those targeting AGE formation or PKC signaling. Considering the clinical trial data concerning hyperglycemia itself, the major issue with these studies may simply involve timing of intervention. Clinical trials for antioxidants typically utilize patients already at a high risk for CVD, and interventions for hyperglycemia in these patients showed a similar lack of beneficial effect. The use of antioxidants early following the diagnosis of diabetes, especially coupled with intensive glycemic control, may provide additional benefit later in life. Consistent with this idea, intensive treatment to lower hyperglycemia in the DCCT and UKPDS trials demonstrate the most striking benefit in long-term follow-up studies 10 years after cessation of differential treatment; no longterm follow-up studies have been performed for antioxidant therapies. Therefore, more research is needed in this area if we are to translate the volumes of cell and molecular biology, animal research, and clinical trials into effective therapeutic strategies.

\section{Acknowledgments}

This work was funded by the American Diabetes Association Junior Faculty Award 1-10-JF-39 to A. W. Orr, by a Malcolm Feist Predoctoral Fellowship to S. D. Funk, and by the Interdisciplinary Toxicology Program Superior Toxicology Fellowship to A. Yurdagul Jr.

\section{References}

[1] R. Klingenberg and G. K. Hansson, "Treating inflammation in atherosclerotic cardiovascular disease: emerging therapies," European Heart Journal, vol. 30, no. 23, pp. 2838-2844, 2009.

[2] V. L. Roger, A. S. Go, D. M. Lloyd-Jones et al., "Heart disease and stroke statistics-2011 update: a report from the American heart association," Circulation, vol. 123, no. 4, pp. e18-e209, 2010.

[3] R. Collins, J. Armitage, S. Parish et al., "Effects of cholesterollowering with simvastatin on stroke and other major vascular events in 20536 people with cerebrovascular disease or other high-risk conditions," The Lancet, vol. 363, no. 9411, pp. 757767, 2004.

[4] P. Thavendiranathan, A. Bagai, M. A. Brookhart, and N. K. Choudhry, "Primary prevention of cardiovascular diseases with statin therapy: a meta-analysis of randomized controlled trials," Archives of Internal Medicine, vol. 166, no. 21, pp. 2307-2313, 2006.

[5] K. K. Ray, S. R. K. Seshasai, S. Erqou et al., "Statins and all-cause mortality in high-risk primary prevention: a metaanalysis of 11 randomized controlled trials involving 65,229 participants," Archives of Internal Medicine, vol. 170, no. 12, pp. 1024-1031, 2010.

[6] S. Yusuf, S. Reddy, S. Ônpuu, and S. Anand, "Global burden of cardiovascular diseases. Part I: general considerations, the epidemiologic transition, risk factors, and impact of urbanization," Circulation, vol. 104, no. 22, pp. 2746-2753, 2001.

[7] S. L. Gortmaker, B. A. Swinburn, D. Levy et al., "Changing the future of obesity: science, policy, and action," The Lancet, vol. 378, no. 9793, pp. 838-847, 2011.

[8] R. Ross, "Atherosclerosis-an inflammatory disease," New England Journal of Medicine, vol. 340, no. 2, pp. 115-126, 1999.

[9] P. Libby, P. M. Ridker, and G. K. Hansson, "Progress and challenges in translating the biology of atherosclerosis," Nature, vol. 473, no. 7347, pp. 317-325, 2011.

[10] P. Libby, P. M. Ridker, and G. K. Hansson, "Inflammation in atherosclerosis. From pathophysiology to practice," Journal of the American College of Cardiology, vol. 54, no. 23, pp. 21292138, 2009.

[11] A. Daugherty, H. Lu, D. A. Howatt, and D. L. Rateri, "Modes of defining atherosclerosis in mouse models: relative merits 
and evolving standards," Methods in Molecular Biology, vol. 573, pp. 1-15, 2009.

[12] M. A. Gimbrone Jr, J. N. Topper, T. Nagel, K. R. Anderson, and G. Garcia-Cardeña, "Endothelial dysfunction, hemodynamic forces, and atherogenesis," Annals of the New York Academy of Sciences, vol. 902, pp. 230-240, 2000.

[13] C. Hahn and M. A. Schwartz, "Mechanotransduction in vascular physiology and atherogenesis," Nature Reviews Molecular Cell Biology, vol. 10, no. 1, pp. 53-62, 2009.

[14] K. Kornerup, B. G. Nordestgaard, T. K. Jensen et al., "Transendothelial exchange of low-density lipoprotein is unaffected by the presence of severe atherosclerosis," Cardiovascular Research, vol. 64, no. 2, pp. 337-345, 2004.

[15] L. R. Tannock and V. L. King, "Proteoglycan mediated lipoprotein retention: a mechanism of diabetic atherosclerosis," Reviews in Endocrine and Metabolic Disorders, vol. 9, no. 4, pp. 289-300, 2008.

[16] C. Mazière and J. C. Mazière, "Activation of transcription factors and gene expression by oxidized low-density lipoprotein," Free Radical Biology and Medicine, vol. 46, no. 2, pp. 127-137, 2009.

[17] E. Falk and A. Fernandez-Ortiz, "Role of thrombosis in atherosclerosis and its complications," American Journal of Cardiology, vol. 75, no. 6, pp. 3B-11B, 1995.

[18] P. Libby, "The molecular mechanisms of the thrombotic complications of atherosclerosis," Journal of Internal Medicine, vol. 263, no. 5, pp. 517-527, 2008.

[19] P. Libby, "Molecular and cellular mechanisms of the thrombotic complications of atherosclerosis," Journal of lipid research, vol. 263, supplement 5, pp. S352-S357, 2009.

[20] F. Henschen, "On the term diabetes in the works of Aretaeus and Galen," Medical History, vol. 13, no. 2, pp. 190-192, 1969.

[21] S. Wild, G. Roglic, A. Green, R. Sicree, and H. King, "Global prevalence of diabetes: estimates for the year 2000 and projections for 2030," Diabetes Care, vol. 27, no. 5, pp. 10471053, 2004.

[22] R. R. Little and D. B. Sacks, "HbAlc: how do we measure it and what does it mean?" Current Opinion in Endocrinology, Diabetes and Obesity, vol. 16, no. 2, pp. 113-118, 2009.

[23] H. Ding and C. R. Triggle, "Endothelial cell dysfunction and the vascular complications associated with type 2 diabetes: assessing the health of the endothelium," Vascular Health and Risk Management, vol. 1, no. 1, pp. 55-71, 2005.

[24] N. Winer and J. R. Sowers, "Epidemiology of diabetes," Journal of Clinical Pharmacology, vol. 44, no. 4, pp. 397-405, 2004.

[25] L. Whiteley, S. Padmanabhan, D. Hole, and C. Isles, "Should diabetes be considered a coronary heart disease risk equivalent? results from 25 years of follow-up in the Renfrew and Paisley survey," Diabetes Care, vol. 28, no. 7, pp. 1588-1593, 2005.

[26] P. Pajunen, M. R. Taskinen, M. S. Nieminen, and M. Syvänne, "Angiographic severity and extent of coronary artery disease in patients with type 1 diabetes mellitus," American Journal of Cardiology, vol. 86, no. 10, pp. 1080-1085, 2000.

[27] P. R. Moreno, A. M. Murcia, I. F. Palacios et al., "Coronary composition and macrophage infiltration in atherectomy specimens from patients with diabetes mellitus," Circulation, vol. 102, no. 18, pp. 2180-2184, 2000.

[28] A. P. Burke, F. D. Kolodgie, A. Zieske et al., "Morphologic findings of coronary atherosclerotic plaques in diabetics: a postmortem study," Arteriosclerosis, Thrombosis, and Vascular Biology, vol. 24, no. 7, pp. 1266-1271, 2004.
[29] D. de Zeeuw and S. J. L. Bakker, "Does the metabolic syndrome add to the diagnosis and treatment of cardiovascular disease?" Nature Clinical Practice Cardiovascular Medicine, vol. 5, supplement 1, pp. S10-S14, 2008.

[30] K. Marinou, D. Tousoulis, A. S. Antonopoulos, E. Stefanadi, and C. Stefanadis, "Obesity and cardiovascular disease: from pathophysiology to risk stratification," International Journal of Cardiology, vol. 138, no. 1, pp. 3-8, 2010.

[31] L. F. van Gaal, I. L. Mertens, and C. E. de Block, "Mechanisms linking obesity with cardiovascular disease," Nature, vol. 444, no. 7121, pp. 875-880, 2006.

[32] M. J. Jarvisalo, M. Raitakari, J. O. Toikka et al., "Endothelial dysfunction and increased arterial intima-media thickness in children with type 1 diabetes," Circulation, vol. 109, no. 14, pp. 1750-1755, 2004.

[33] H. C. McGill Jr, C. A. McMahan, A. W. Zieske, G. T. Malcom, R. E. Tracy, and J. P. Strong, "Effects of nonlipid risk factors on atherosclerosis in youth with a favorable lipoprotein profile," Circulation, vol. 103, no. 11, pp. 1546-1550, 2001.

[34] M. J. Järvisalo, A. Putto-Laurila, L. Jartti et al., "Carotid artery intima-media thickness in children with type 1 diabetes," Diabetes, vol. 51, no. 2, pp. 493-498, 2002.

[35] S. Lenzen, "The mechanisms of alloxan- and streptozotocininduced diabetes," Diabetologia, vol. 51, no. 2, pp. 216-226, 2008.

[36] S. Oehen, P. S. Ohashi, P. Aichele, K. Burki, H. Hengartner, and R. M. Zinkernagel, "Vaccination or tolerance to prevent diabetes," European Journal of Immunology, vol. 22, no. 12, pp. 3149-3153, 1992.

[37] J. Wang, T. Takeuchi, S. Tanaka et al., "A mutation in the insulin 2 gene induces diabetes with severe pancreatic $\beta$-cell dysfunction in the Mody mouse," Journal of Clinical Investigation, vol. 103, no. 1, pp. 27-37, 1999.

[38] J. Y. Jun, Z. Ma, and L. Segar, "Spontaneously diabetic Ins2(+/Akita): apoe-deficient mice exhibit exaggerated hypercholesterolemia and atherosclerosis," American Journal of Physiology-Endocrinology and Metabolism, vol. 301, no. 1, pp. E145-E154, 2011.

[39] C. Zhou, B. Pridgen, N. King, J. Xu, and J. L. Breslow, "Hyperglycemic Ins2AkitaLdlr-/- mice show severely elevated lipid levels and increased atherosclerosis: a model of type 1 diabetic macrovascular disease," Journal of Lipid Research, vol. 52, no. 8, pp. 1483-1493, 2011.

[40] H. Ding, M. Hashem, W. B. Wiehler et al., "Endothelial dysfunction in the streptozotocin-induced diabetic apoE-deficient mouse," British Journal of Pharmacology, vol. 146, no. 8, pp. 1110-1118, 2005.

[41] C. B. Renard, F. Kramer, F. Johansson et al., "Diabetes and diabetes-associated lipid abnormalities have distinct effects on initiation and progression of atherosclerotic lesions," Journal of Clinical Investigation, vol. 114, no. 5, pp. 659-668, 2004.

[42] M. I. J. Uusitupa, L. K. Niskanen, O. Siitonen, E. Voutilainen, and K. Pyorala, "Ten-year cardiovascular mortality in relation to risk factors and abnormalities in lipoprotein composition in type 2 (non-insulin-dependent) diabetic and nondiabetic subjects," Diabetologia, vol. 36 , no. 11, pp. 11751184, 1993.

[43] J. Kuusisto, L. Mykkanen, K. Pyorala, and M. Laakso, "Noninsulin-dependent diabetes and its metabolic control are important predictors of stroke in elderly subjects," Stroke, vol. 25, no. 6, pp. 1157-1164, 1994. 
[44] The DCCT Group, "The effect of intensive treatment of diabetes on the development and progression of longterm complications in insulin-dependent diabetes mellitus. The diabetes control and complications trial research group," The New England Journal of Medicine, vol. 329, no. 14, pp. 977-986, 1993.

[45] D. M. Nathan, P. A. Cleary, J. Y. C. Backlund et al., "Intensive diabetes treatment and cardiovascular disease in patients with type 1 diabetes," New England Journal of Medicine, vol. 353, no. 25, pp. 2643-2653, 2005.

[46] The UKPDS Group, "Intensive blood-glucose control with sulphonylureas or insulin compared with conventional treatment and risk of complications in patients with type 2 diabetes (UKPDS 33). UK prospective diabetes study (UKPDS) group," The Lancet, vol. 352, no. 9131, pp. 837-853, 1998.

[47] R. R. Holman, S. K. Paul, M. A. Bethel, D. R. Matthews, and H. A. W. Neil, "10-Year follow-up of intensive glucose control in type 2 diabetes," New England Journal of Medicine, vol. 359, no. 15, pp. 1577-1589, 2008.

[48] H. C. Gerstein, W. T. Friedewald, J. B. Buse et al., "Effects of intensive glucose lowering in type 2 diabetes," New England Journal of Medicine, vol. 358, no. 24, pp. 2545-2559, 2008.

[49] A. Patel, S. MacMahon, J. Chalmers et al., "Intensive blood glucose control and vascular outcomes in patients with type 2 diabetes," New England Journal of Medicine, vol. 358, no. 24, pp. 2560-2572, 2008.

[50] W. Duckworth, C. Abraira, T. Moritz et al., "Glucose control and vascular complications in veterans with type 2 diabetes," New England Journal of Medicine, vol. 360, no. 2, pp. 129-139, 2009.

[51] H. F. Galley and N. R. Webster, "Physiology of the endothelium," British Journal of Anaesthesia, vol. 93, no. 1, pp. 105113, 2004.

[52] J. S. Pober and W. C. Sessa, "Evolving functions of endothelial cells in inflammation," Nature Reviews Immunology, vol. 7, no. 10, pp. 803-815, 2007.

[53] A. W. Orr, J. M. Sanders, M. Bevard, E. Coleman, I. J. Sarembock, and M. A. Schwartz, "The subendothelial extracellular matrix modulates NF- $\kappa$ B activation by flow: a potential role in atherosclerosis," Journal of Cell Biology, vol. 169, no. 1, pp. 191-202, 2005.

[54] A. W. Orr, R. Stockton, M. B. Simmers et al., "Matrixspecific p21-activated kinase activation regulates vascular permeability in atherogenesis," Journal of Cell Biology, vol. 176, no. 5, pp. 719-727, 2007.

[55] K. Ley, C. Laudanna, M. I. Cybulsky, and S. Nourshargh, "Getting to the site of inflammation: the leukocyte adhesion cascade updated," Nature Reviews Immunology, vol. 7, no. 9, pp. 678-689, 2007.

[56] M. C. Bourdillon, R. N. Poston, C. Covacho, E. Chignier, G. Bricca, and J. L. McGregor, "ICAM-1 deficiency reduces atherosclerotic lesions in double-knockout mice (ApoE(-/)/ICAM-1(-/-)) fed a fat or a chow diet," Arteriosclerosis, Thrombosis, and Vascular Biology, vol. 20, no. 12, pp. 26302635, 2000.

[57] M. I. Cybulsky, K. Iiyama, H. Li et al., "A major role for VCAM-1, but not ICAM-1, in early atherosclerosis," Journal of Clinical Investigation, vol. 107, no. 10, pp. 1255-1262, 2001.

[58] K. Ley and Y. Huo, "VCAM-1 is critical in atherosclerosis," Journal of Clinical Investigation, vol. 107, no. 10, pp. 12091210, 2001.
[59] G. C. Gurtner, V. Davis, H. Li, M. J. McCoy, A. Sharpe, and M. I. Cybulsky, "Targeted disruption of the murine VCAM1 gene: essential role of VCAM-1 in chorioallantoic fusion and placentation," Genes and Development, vol. 9, no. 1, pp. 1-14, 1995.

[60] L. Gu, Y. Okada, S. K. Clinton et al., "Absence of monocyte chemoattractant protein-1 reduces atherosclerosis in low density lipoprotein receptor-deficient mice," Molecular Cell, vol. 2, no. 2, pp. 275-281, 1998.

[61] J. S. Pober and W. Min, "Endothelial cell dysfunction, injury and death," Handbook of Experimental Pharmacology, no. 176, part 2, pp. 135-156, 2006.

[62] G. M. Buga, M. E. Gold, J. M. Fukuto, and L. J. Ignarro, "Shear stress-induced release of nitric oxide from endothelial cells grown on beads," Hypertension, vol. 17, no. 2, pp. 187193, 1991.

[63] J. L. Amezcua, G. J. Dusting, R. M. J. Palmer, and S. Moncada, "Acetylcholine induces vasodilatation in the rabbit isolated heart through the release of nitric oxide, the endogenous nitrovasodilator," British Journal of Pharmacology, vol. 95, no. 3, pp. 830-834, 1988.

[64] V. Lahera, M. G. Salom, M. J. Fiksen-Olsen, and J. C. Romero, "Mediatory role of endothelium-derived nitric oxide in renal vasodilatory and excretory effects of bradykinin," American Journal of Hypertension, vol. 4, no. 3, part 1, pp. 260-262, 1991.

[65] U. Scherrer, D. Randin, P. Vollenweider, L. Vollenweider, and P. Nicod, "Nitric oxide release accounts for insulin's vascular effects in humans," Journal of Clinical Investigation, vol. 94, no. 6, pp. 2511-2515, 1994.

[66] H. O. Steinberg, G. Brechtel, A. Johnson, N. Fineberg, and A. D. Baron, "Insulin-mediated skeletal muscle vasodilation is nitric oxide dependent. A novel action of insulin to increase nitric oxide release," Journal of Clinical Investigation, vol. 94, no. 3, pp. 1172-1179, 1994.

[67] H. Chen, M. Montagnani, T. Funahashi, I. Shimomura, and M. J. Quon, "Adiponectin stimulates production of nitric oxide in vascular endothelial cells," Journal of Biological Chemistry, vol. 278, no. 45, pp. 45021-45026, 2003.

[68] Y. Xia, A. L. Tsai, V. Berka, and J. L. Zweier, "Superoxide generation from endothelial nitric-oxide synthase: a $\mathrm{Ca} 2+/$ calmodulin-dependent and tetrahydrobiopterin regulatory process," Journal of Biological Chemistry, vol. 273, no. 40, pp. 25804-25808, 1998.

[69] C. Antoniades, C. Shirodaria, P. Leeson et al., "Association of plasma asymmetrical dimethylarginine (ADMA) with elevated vascular superoxide production and endothelial nitric oxide synthase uncoupling: implications for endothelial function in human atherosclerosis," European Heart Journal, vol. 30, no. 9, pp. 1142-1150, 2009.

[70] C. Dumitrescu, R. Biondi, Y. Xia et al., "Myocardial ischemia results in tetrahydrobiopterin (BH4) oxidation with impaired endothelial function ameliorated by BHIN4," Proceedings of the National Academy of Sciences of the United States of America, vol. 104, no. 38, pp. 15081-15086, 2007.

[71] C. A. Chen, T. Y. Wang, S. Varadharaj et al., "S-glutathionylation uncouples eNOS and regulates its cellular and vascular function," Nature, vol. 468, no. 7327, pp. 1115-1120, 2010.

[72] F. Giacco and M. Brownlee, "Oxidative stress and diabetic complications," Circulation Research, vol. 107, no. 9, pp. 1058-1070, 2010.

[73] Z. Fatehi-Hassanabad, C. B. Chan, and B. L. Furman, "Reactive oxygen species and endothelial function in diabetes," 
European Journal of Pharmacology, vol. 636, no. 1-3, pp. 8$17,2010$.

[74] N. G. Oberprieler, W. Roberts, A. M. Graham, S. HomerVanniasinkam, and K. M. Naseem, "cGMP-independent inhibition of integrin $\alpha \operatorname{IIb} \beta 3$-mediated platelet adhesion and outside-in signalling by nitric oxide," FEBS Letters, vol. 581, no. 7, pp. 1529-1534, 2007.

[75] W. Roberts, R. Riba, S. Homer-Vanniasinkam, R. W. Farndale, and K. M. Naseem, "Nitric oxide specifically inhibits integrin-mediated platelet adhesion and spreading on collagen," Journal of Thrombosis and Haemostasis, vol. 6, no. 12, pp. 2175-2185, 2008.

[76] A. Chigaev, Y. Smagley, and L. A. Sklar, "Nitric oxide/cGMP pathway signaling actively down-regulates $\alpha 4 \beta 1$-integrin affinity: an unexpected mechanism for inducing cell de-adhesion," BMC Immunology, vol. 12, p. 28, 2011.

[77] R. Draijer, D. E. Atsma, A. van der Laarse, and V. W. M. van Hinsbergh, "cGMP and nitric oxide modulate thrombininduced endothelial permeability: regulation via different pathways in human aortic and umbilical vein endothelial cells," Circulation Research, vol. 76, no. 2, pp. 199-208, 1995.

[78] K. Matsushita, C. N. Morrell, B. Cambien et al., "Nitric oxide regulates exocytosis by $\mathrm{S}$-nitrosylation of $\mathrm{N}$-ethylmaleimidesensitive factor," Cell, vol. 115, no. 2, pp. 139-150, 2003.

[79] R. de Caterina, P. Libby, H. B. Peng et al., "Nitric oxide decreases cytokine-induced endothelial activation. Nitric oxide selectively reduces endothelial expression of adhesion molecules and proinflammatory cytokines," Journal of Clinical Investigation, vol. 96, no. 1, pp. 60-68, 1995.

[80] B. V. Khan, D. G. Harrison, M. T. Olbrych, R. W. Alexander, and R. M. Medford, "Nitric oxide regulates vascular cell adhesion molecule 1 gene expression and redox-sensitive transcriptional events in human vascular endothelial cells," Proceedings of the National Academy of Sciences of the United States of America, vol. 93, no. 17, pp. 9114-9119, 1996.

[81] S. C. Tai, G. B. Robb, and P. A. Marsden, "Endothelial nitric oxide synthase: a new paradigm for gene regulation in the injured blood vessel," Arteriosclerosis, Thrombosis, and Vascular Biology, vol. 24, no. 3, pp. 405-412, 2004.

[82] D. J. Lefer, S. P. Jones, W. G. Girod et al., "Leukocyteendothelial cell interactions in nitric oxide synthase- deficient mice," American Journal of Physiology-Heart and Circulatory Physiology, vol. 276, no. 6, part 2, pp. H1943-H1950, 1999.

[83] R. D. Rudic, E. G. Shesely, N. Maeda, O. Smithies, S. S. Segal, and W. C. Sessa, "Direct evidence for the importance of endothelium-derived nitric oxide in vascular remodeling," Journal of Clinical Investigation, vol. 101, no. 4, pp. 731-736, 1998.

[84] M. Ozaki, S. Kawashima, T. Yamashita et al., "Overexpression of endothelial nitric oxide synthase accelerates atherosclerotic lesion formation in apoE-deficient mice," Journal of Clinical Investigation, vol. 110, no. 3, pp. 331-340, 2002.

[85] T. S. Schmidt, E. McNeill, G. Douglas et al., "Tetrahydrobiopterin supplementation reduces atherosclerosis and vascular inflammation in apolipoprotein E-knockout mice," Clinical Science, vol. 119, no. 3, pp. 131-142, 2010.

[86] L. Li, W. Chen, A. Rezvan, H. Jo, and D. G. Harrison, "Tetrahydrobiopterin deficiency and nitric oxide synthase uncoupling contribute to atherosclerosis induced by disturbed flow," Arteriosclerosis, Thrombosis, and Vascular Biology, vol. 31, no. 7, pp. 1547-1554, 2011.

[87] Y. Ding, N. D. Vaziri, R. Coulson, V. S. Kamanna, and D. D. Roh, "Effects of simulated hyperglycemia, insulin, and glucagon on endothelial nitric oxide synthase expression," American Journal of Physiology-Endocrinology and Metabolism, vol. 279, no. 1, pp. E11-E17, 2000.

[88] X. L. Du, D. Edelstein, S. Dimmeler, Q. Ju, C. Sui, and M. Brownlee, "Hyperglycemia inhibits endothelial nitric oxide synthase activity by posttranslational modification at the Akt site," Journal of Clinical Investigation, vol. 108, no. 9, pp. 1341-1348, 2001.

[89] M. Hamuro, J. Polan, M. Natarajan, and S. Mohan, "High glucose induced nuclear factor $\kappa \mathrm{B}$ mediated inhibition of endothelial cell migration," Atherosclerosis, vol. 162, no. 2, pp. 277-287, 2002.

[90] P. Luppi, V. Cifarelli, H. Tse, J. Piganelli, and M. Trucco, "Human C-peptide antagonises high glucose-induced endothelial dysfunction through the nuclear factor- $\kappa \mathrm{B}$ pathway," Diabetologia, vol. 51, no. 8, pp. 1534-1543, 2008.

[91] R. Piga, Y. Naito, S. Kokura, O. Handa, and T. Yoshikawa, "Short-term high glucose exposure induces monocyteendothelial cells adhesion and transmigration by increasing VCAM-1 and MCP-1 expression in human aortic endothelial cells," Atherosclerosis, vol. 193, no. 2, pp. 328-334, 2007.

[92] M. Morigi, S. Angioletti, B. Imberti et al., "Leukocyte-endothelial interaction is augmented by high glucose concentrations and hyperglycemia in a NF-kB-dependent fashion," Journal of Clinical Investigation, vol. 101, no. 9, pp. 19051915, 1998.

[93] I. Manduteanu, M. Voinea, G. Serban, and M. Simionescu, "High glucose induces enhanced monocyte adhesion to valvular endothelial cells via a mechanism involving ICAM-1, VCAM-1 and CD18," Endothelium, vol. 6, no. 4, pp. 315-324, 1999.

[94] C. Esposito, G. Fasoli, A. Plati et al., "Long-term exposure to high glucose up-regulates VCAM-induced endothelial cell adhesiveness to PBMC," Kidney International, vol. 59, no. 5, pp. 1842-1849, 2001.

[95] L. Piconi, L. Quagliaro, R. da Ros et al., "Intermittent high glucose enhances ICAM-1, VCAM-1, E-selectin and interleukin-6 expression in human umbilical endothelial cells in culture: the role of poly(ADP-ribose) polymerase," Journal of Thrombosis and Haemostasis, vol. 2, no. 8, pp. 1453-1459, 2004.

[96] J. A. Kim, J. A. Berliner, R. D. Natarajan, and J. L. Nadler, "Evidence that glucose increases monocyte binding to human aortic endothelial cells," Diabetes, vol. 43, no. 9, pp. 11031107, 1994.

[97] A. El-Osta, D. Brasacchio, D. Yao et al., "Transient high glucose causes persistent epigenetic changes and altered gene expression during subsequent normoglycemia," Journal of Experimental Medicine, vol. 205, no. 10, pp. 2409-2417, 2008.

[98] R. P. Patel, D. Moellering, J. Murphy-Ullrich, H. Jo, J. S. Beckman, and V. M. Darley-Usmar, "Cell signaling by reactive nitrogen and oxygen species in atherosclerosis," Free Radical Biology and Medicine, vol. 28, no. 12, pp. 1780-1794, 2000.

[99] G. P. Sorescu, H. Song, S. L. Tressel et al., "Bone morphogenic protein 4 produced in endothelial cells by oscillatory shear stress induces monocyte adhesion by stimulating reactive oxygen species production from a Nox1-based NADPH oxidase," Circulation Research, vol. 95, no. 8, pp. 773-779, 2004.

[100] A. W. Orr, C. Hahn, B. R. Blackman, and M. A. Schwartz, "P21-activated kinase signaling regulates oxidant-dependent NF- $\kappa$ B activation by flow," Circulation Research, vol. 103, no. 6, pp. 671-679, 2008. 
[101] D. Han, M. D. Ybanez, S. Ahmadi, K. Yeh, and N. Kaplowitz, "Redox regulation of tumor necrosis factor signaling," Antioxidants and Redox Signaling, vol. 11, no. 9, pp. 22452263, 2009.

[102] Q. Li and J. F. Engelhardt, "Interleukin- $1 \beta$ induction of $N F \kappa B$ is partially regulated by $\mathrm{H} 2 \mathrm{O} 2$-mediated activation of $\mathrm{NF} \kappa \mathrm{B}$ inducing kinase," Journal of Biological Chemistry, vol. 281, no. 3, pp. 1495-1505, 2006.

[103] J. Liu, F. Yang, X. -P. Yang, M. Jankowski, and P. J. Pagan$\mathrm{o}$, "NAD $(\mathrm{P}) \mathrm{H}$ oxidase mediates angiotensin II-induced vascular macrophage infiltration and medial hypertrophy," Arteriosclerosis, Thrombosis, and Vascular Biology, vol. 23, no. 5, pp. 776-782, 2003.

[104] L. Cominacini, A. F. Pasini, U. Garbin et al., "Oxidized low density lipoprotein (ox-LDL) binding to ox-LDL receptor-1 in endothelial cells induces the activation of NF- $\kappa \mathrm{B}$ through an increased production of intracellular reactive oxygen species," Journal of Biological Chemistry, vol. 275, no. 17, pp. 12633-12638, 2000.

[105] R. P. Brandes and K. Schroder, "Differential vascular functions of Nox family NADPH oxidases," Current Opinion in Lipidology, vol. 19, no. 5, pp. 513-518, 2008.

[106] G. Gloire, S. Legrand-Poels, and J. Piette, "NF- $\kappa$ B activation by reactive oxygen species: fifteen years later," Biochemical Pharmacology, vol. 72, no. 11, pp. 1493-1505, 2006.

[107] C. G. Kevil, T. Oshima, B. Alexander, L. L. Coe, and J. S. Alexander, " $\mathrm{H}_{2} \mathrm{O}_{2}$-mediated permeability: role of MAPK and occludin," American Journal of Physiology-Cell Physiology, vol. 279, no. 1, pp. C21-C30, 2000.

[108] N. Okayama, C. G. Kevil, L. Correia et al., "Nitric oxide enhances hydrogen peroxide-mediated endothelial permeability in vitro," American Journal of Physiology-Cell Physiology, vol. 273, no. 5, part 1, pp. C1581-C1587, 1997.

[109] J. Galle, T. Hansen-Hagge, C. Wanner, and S. Seibold, "Impact of oxidized low density lipoprotein on vascular cells," Atherosclerosis, vol. 185, no. 2, pp. 219-226, 2006.

[110] U. Landmesser, S. Dikalov, S. R. Price et al., "Oxidation of tetrahydrobiopterin leads to uncoupling of endothelial cell nitric oxide synthase in hypertension," Journal of Clinical Investigation, vol. 111, no. 8, pp. 1201-1209, 2003.

[111] S. P. Wolff, Z. Y. Jiang, and J. V. Hunt, "Protein glycation and oxidative stress in diabetes mellitus and ageing," Free Radical Biology and Medicine, vol. 10, no. 5, pp. 339-352, 1991.

[112] U. J. Eriksson and L. A. H. Borg, "Diabetes and embryonic malformations: role of substrate-induced free- oxygen radical production for dysmorphogenesis in cultured rat embryos," Diabetes, vol. 42, no. 3, pp. 411-419, 1993.

[113] S. Cai, J. Khoo, and K. M. Channon, "Augmented BH4 by gene transfer restores nitric oxide synthase function in hyperglycemic human endothelial cells," Cardiovascular Research, vol. 65, no. 4, pp. 823-831, 2005.

[114] Z. Y. Jiang, A. C. S. Woollard, and S. P. Wolff, "Hydrogen peroxide production during experimental protein glycation," FEBS Letters, vol. 268, no. 1, pp. 69-71, 1990.

[115] D. P. Gelain, R. J. S. Dalmolin, V. L. Belau, J. C. F. Moreira, F. Klamt, and M. A. A. Castro, "A systematic review of human antioxidant genes," Frontiers in Bioscience, vol. 14, no. 12, pp. 4457-4463, 2009.

[116] L. J. Mandarino, J. Finlayson, and J. R. Hassell, "High glucose downregulates glucose transport activity in retinal capillary pericytes but not endothelial cells," Investigative Ophthalmology and Visual Science, vol. 35, no. 3, pp. 964-972, 1994.
[117] M. H. Zou, C. Shi, and R. A. Cohen, "Oxidation of the zincthiolate complex and uncoupling of endothelial nitric oxide synthase by peroxynitrite," Journal of Clinical Investigation, vol. 109, no. 6, pp. 817-826, 2002.

[118] G. Basta, G. Lazzerini, S. del Turco, G. M. Ratto, A. M. Schmidt, and R. de Caterina, "At least 2 distinct pathways generating reactive oxygen species mediate vascular cell adhesion molecule-1 induction by advanced glycation end products," Arteriosclerosis, Thrombosis, and Vascular Biology, vol. 25, no. 7, pp. 1401-1407, 2005.

[119] T. Nishikawa, D. Edelstein, X. L. Du et al., "Normalizing mitochondrial superoxide production blocks three pathways of hyperglycaemic damage," Nature, vol. 404, no. 6779, pp. 787-790, 2000.

[120] R. Recchioni, F. Marcheselli, F. Moroni, and C. Pieri, "Apoptosis in human aortic endothelial cells induced by hyperglycemic condition involves mitochondrial depolarization and is prevented by N-acetyl-L-cysteine," Metabolism, vol. 51, no. 11, pp. 1384-1388, 2002.

[121] H. Tsuneki, N. Sekizaki, T. Suzuki et al., "Coenzyme Q10 prevents high glucose-induced oxidative stress in human umbilical vein endothelial cells," European Journal of Pharmacology, vol. 566, no. 1-3, pp. 1-10, 2007.

[122] L. Quagliaro, L. Piconi, R. Assaloni et al., "Intermittent high glucose enhances ICAM-1, VCAM-1 and E-selectin expression in human umbilical vein endothelial cells in culture: the distinct role of protein kinase $\mathrm{C}$ and mitochondrial superoxide production," Atherosclerosis, vol. 183, no. 2, pp. 259267, 2005.

[123] L. Quagliaro, L. Piconi, R. Assaloni, R. da Ros, C. Szabó, and A. Ceriello, "Primary role of superoxide anion generation in the cascade of events leading to endothelial dysfunction and damage in high glucose treated HUVEC," Nutrition, $\mathrm{Me}$ tabolism and Cardiovascular Diseases, vol. 17, no. 4, pp. 257267, 2007.

[124] P. S. Tsao, J. Niebauer, R. Buitrago et al., "Interaction of diabetes and hypertension on determinants of endothelial adhesiveness," Arteriosclerosis, Thrombosis, and Vascular Biology, vol. 18, no. 6, pp. 947-953, 1998.

[125] X.-Q. Yang, Y.-Y. Wang, and A. F. Chen, "Increased superoxide contributes to enhancement of vascular contraction in INS2AKITA diabetic mice, an autosomal dominant mutant model," Clinical and Experimental Pharmacology and Physiology, vol. 35, no. 9, pp. 1097-1103, 2008.

[126] A. Cumaoglu, G. Ozansoy, A. M. Irat, A. Aricioglu, C. Karasu, and N. Ari, "Effect of long term, non cholesterol lowering dose of fluvastatin treatment on oxidative stress in brain and peripheral tissues of streptozotocin-diabetic rats," European Journal of Pharmacology, vol. 654, no. 1, pp. 80-85, 2011.

[127] B. Tesfamariam and R. A. Cohen, "Free radicals mediate endothelial cell dysfunction caused by elevated glucose," American Journal of Physiology-Heart and Circulatory Physiology, vol. 263, no. 2, part 2, pp. H321-H326, 1992.

[128] G. M. Pieper, "Divergent actions of chronic insulin treatment in vivo versus acute treatment ex vivo on diabetic-induced endothelial dysfunction," Life Sciences, vol. 60, no. 25, pp. PL371-PL376, 1997.

[129] G. M. Pieper and W. Siebeneich, "Oral administration of the antioxidant, $\mathrm{N}$-acetylcysteine, abrogates diabetesinduced endothelial dysfunction," Journal of Cardiovascular Pharmacology, vol. 32, no. 1, pp. 101-105, 1998. 
[130] P. Lewis, N. Stefanovic, J. Pete et al., "Lack of the antioxidant en-zyme glutathione peroxidase- 1 accelerates atherosclerosis in diabetic apolipoprotein E-deficient mice," Circulation, vol. 115, no. 16, pp. 2178-2187, 2007.

[131] S. V. Brodsky, O. Gealekman, J. Chen et al., "Prevention and reversal of premature endothelial cell senescence and vasculopathy in obesity-induced diabetes by ebselen," Circulation Research, vol. 94, no. 3, pp. 377-384, 2004.

[132] P. Chew, D. Y. C. Yuen, P. Koh et al., "Site-specific antiatherogenic effect of the antioxidant ebselen in the diabetic apolipoprotein E-deficient mouse," Arteriosclerosis, Thrombosis, and Vascular Biology, vol. 29, no. 6, pp. 823-830, 2009.

[133] C. L. Allen and U. Bayraktutan, "Antioxidants attenuate hyperglycaemia-mediated brain endothelial cell dysfunction and blood-brain barrier hyperpermeability," Diabetes, Obesity and Metabolism, vol. 11, no. 5, pp. 480-490, 2009.

[134] L. Dang, J. P. Seale, and X. Qu, "High glucose-induced human umbilical vein endothelial cell hyperpermeability is dependent on protein kinase $\mathrm{C}$ activation and independent of the $\mathrm{Ca}^{2+}$-nitric oxide signalling pathway," Clinical and Experimental Pharmacology and Physiology, vol. 32, no. 9, pp. 771-776, 2005.

[135] G. R. Drummond, S. Selemidis, K. K. Griendling, and C. G. Sobey, "Combating oxidative stress in vascular disease: NADPH oxidases as therapeutic targets," Nature Reviews Drug Discovery, vol. 10, no. 6, pp. 453-471, 2011.

[136] S. Yusuf, G. Dagenais, J. Pogue, J. Bosch, and P. Sleight, "Vitamin E supplementation and cardiovascular events in highrisk patients. The heart outcomes prevention evaluation study investigators," The New England Journal of Medicine, vol. 342, no. 3, pp. 154-160, 2000.

[137] M. Boaz, S. Smetana, T. Weinstein et al., "Secondary prevention with antioxidants of cardiovascular disease in endstage renal disease (SPACE): randomised placebo-controlled trial," The Lancet, vol. 356, no. 9237, pp. 1213-1218, 2000.

[138] E. M. Lonn, S. Yusuf, V. Dzavik et al., "Effects of Ramipril and vitamin $\mathrm{E}$ on atherosclerosis: the study to evaluate carotid ultrasound changes in patients treated with Ramipril and vitamin E (SECURE)," Circulation, vol. 103, no. 7, pp. 919925, 2001.

[139] M. Sacco, F. Pellegrini, M. C. Roncaglioni, F. Avanzini, G. Tognoni, and A. Nicolucci, "Primary prevention of cardiovascular events with low dose aspirin and vitamin $\mathrm{E}$ in type 2 diabetic patients: results of the primary prevention project (PPP) trial," Diabetes Care, vol. 26, no. 12, pp. 3264-3272, 2003.

[140] S. R. Steinhubl, "Why have antioxidants failed in clinical trials?" American Journal of Cardiology, vol. 101, no. 10, pp. 14D-19D, 2008.

[141] E. S. Slavina, A. Madanat, A. Pankov et al., "Diabetes mellitus and atherosclerosis," New England Journal of Medicine, vol. 317, no. 13, p. 836, 1987.

[142] R. Singh, A. Barden, T. Mori, and L. Beilin, "Advanced glycation end-products: a review," Diabetologia, vol. 44, no. 2, pp. 129-146, 2001.

[143] W. G. John, M. R. Gray, D. L. Bates, and J. L. Beacham, "Enzyme immunoassay-a new technique for estimating hemoglobin A1c," Clinical Chemistry, vol. 39, no. 4, pp. 663666, 1993.

[144] T. P. Degenhardt, S. R. Thorpe, and J. W. Baynes, "Chemical modification of proteins by methylglyoxal," Cellular and Molecular Biology (Noisy-le-Grand), vol. 44, no. 7, pp. 11391145, 1998.
[145] M. Brownlee, "Biochemistry and molecular cell biology of diabetic complications," Nature, vol. 414, no. 6865, pp. 813820, 2001.

[146] P. J. Thornalley, “The glyoxalase system: new developments towards functional characterization of a metabolic pathway fundamental to biological life," Biochemical Journal, vol. 269, no. 1, pp. 1-11, 1990.

[147] K. J. Wells-Knecht, D. V. Zyzak, J. E. Litchfield, S. R. Thorpe, and J. W. Baynes, "Mechanism of autoxidative glycosylation: identification of glyoxal and arabinose as intermediates in the autoxidative modification of proteins by glucose," Biochemistry, vol. 34, no. 11, pp. 3702-3709, 1995.

[148] M. C. Wells-Knecht, S. R. Thorpe, and J. W. Baynes, "Pathways of formation of glycoxidation products during glycation of collagen," Biochemistry, vol. 34, no. 46, pp. 15134-15141, 1995.

[149] P. J. Thornalley, "Protecting the genome: defence against nucleotide glycation and emerging role of glyoxalase I overexpression in multidrug resistance in cancer chemotherapy," Biochemical Society Transactions, vol. 31, no. 6, pp. 13721377, 2003.

[150] M. Morcos, X. Du, F. Pfisterer et al., "Glyoxalase-1 prevents mitochondrial protein modification and enhances lifespan in caenorhabditis elegans," Aging Cell, vol. 7, no. 2, pp. 260-269, 2008.

[151] M. Neeper, A. M. Schmidt, J. Brett et al., "Cloning and expression of a cell surface receptor for advanced glycosylation end products of proteins," Journal of Biological Chemistry, vol. 267, no. 21, pp. 14998-15004, 1992.

[152] C. Karasu, "Glycoxidative stress and cardiovascular complications in experimentally-induced diabetes: effects of antioxidant treatment," The Open Cardiovascular Medicine Journal, vol. 4, pp. 240-256, 2010.

[153] S. D. Yan, A. M. Schmidt, G. M. Anderson et al., "Enhanced cellular oxidant stress by the interaction of advanced glycation end products with their receptors/binding proteins," Journal of Biological Chemistry, vol. 269, no. 13, pp. 98899897, 1994.

[154] J. L. Wautier and P. J. Guillausseau, "Advanced glycation end products, their receptors and diabetic angiopathy," Diabetes and Metabolism, vol. 27, no. 5, part 1, pp. 535-542, 2001.

[155] A. M. Schmidt, O. Hori, J. X. Chen et al., "Advanced glycation endproducts interacting with their endothelial receptor induce expression of vascular cell adhesion molecule-1 (VCAM-1) in cultured human endothelial cells and in mice: a potential mechanism for the accelerated vasculopathy of diabetes," Journal of Clinical Investigation, vol. 96, no. 3, pp. 1395-1403, 1995.

[156] K. Higai, A. Shimamura, and K. Matsumoto, "Amadorimodified glycated albumin predominantly induces E-selectin expression on human umbilical vein endothelial cells through NADPH oxidase activation," Clinica Chimica Acta, vol. 367, no. 1-2, pp. 137-143, 2006.

[157] B. Xu, Y. Ji, K. Yao, Y. X. Cao, and A. Ferro, "Inhibition of human endothelial cell nitric oxide synthesis by advanced glycation end-products but not glucose: relevance to diabetes," Clinical Science, vol. 109, no. 5, pp. 439-446, 2005.

[158] B. Xu, R. Chibber, D. Ruggerio, E. Kohner, J. Ritter, and A. Ferro, "Impairment of vascular endothelial nitric oxide synthase activity by advanced glycation end products," FASEB journal, vol. 17, no. 10, pp. 1289-1291, 2003.

[159] L. Gao, W.-H. Liu, N.-N. Luan, C. Feng, and T. Shang, "[Correlation between the expression of high mobility group box 1 and receptor for advanced glycation end products and 
the onset of pre-eclampsia]," Zhonghua Fu Chan Ke Za Zhi, vol. 43, no. 10, pp. 746-750, 2008.

[160] W. Cai, J. C. He, L. Zhu, C. Lu, and H. Vlassara, "Advanced glycation end product (AGE) receptor 1 suppresses cell oxidant stress and activation signaling via EGF receptor," Proceedings of the National Academy of Sciences of the United States of America, vol. 103, no. 37, pp. 13801-13806, 2006.

[161] Y. Ishibashi, T. Matsui, M. Takeuchi, and S. I. Yamagishi, "Vardenafil, an inhibitor of phosphodiesterase-5, blocks advanced glycation end product (AGE)-induced up-regulation of monocyte chemoattractant protein-1 mRNA levels in endothelial cells by suppressing AGE receptor (RAGE) expression via elevation of cGMP," Clinical and Experimental Medicine, vol. 11, no. 2, pp. 131-135, 2011.

[162] D. Yao and M. Brownlee, "Hyperglycemia-induced reactive oxygen species increase expression of the receptor for advanced glycation end products (RAGE) and RAGE ligands," Diabetes, vol. 59, no. 1, pp. 249-255, 2010.

[163] D. R. Sell and V. M. Monnir, "Structure elucidation of a senescence cross-link from human extracellular matrix. Implication of pentoses in the aging process," Journal of Biological Chemistry, vol. 264, no. 36, pp. 21597-21602, 1989.

[164] R. Bucala, K. J. Tracey, and A. Cerami, "Advanced glycosylation products quench nitric oxide and mediate defective endothelium-dependent vasodilatation in experimental diabetes," Journal of Clinical Investigation, vol. 87, no. 2, pp. 432438, 1991.

[165] M. Laga, A. Cottyn, F. van Herreweghe et al., "Methylglyoxal suppresses TNF- $\alpha$-induced NF- $\kappa \mathrm{B}$ activation by inhibiting NF- $\kappa$ B DNA-binding," Biochemical Pharmacology, vol. 74, no. 4, pp. 579-589, 2007.

[166] R. Bucala and H. Vlassara, "Advanced glycosylation end products in diabetic renal and vascular disease," American Journal of Kidney Diseases, vol. 26, no. 6, pp. 875-888, 1995.

[167] H. Tanaka, F. A. Dinenno, K. D. Monahan, C. M. Clevenger, C. A. DeSouza, and D. R. Seals, "Aging, habitual exercise, and dynamic arterial compliance," Circulation, vol. 102, no. 11, pp. 1270-1275, 2000.

[168] B. Corman, M. Duriez, P. Poitevin et al., "Aminoguanidine prevents age-related arterial stiffening and cardiac hypertrophy," Proceedings of the National Academy of Sciences of the United States of America, vol. 95, no. 3, pp. 1301-1306, 1998.

[169] A. Goldin, J. A. Beckman, A. M. Schmidt, and M. A. Creager, "Advanced glycation end products: sparking the development of diabetic vascular injury," Circulation, vol. 114, no. 6, pp. 597-605, 2006.

[170] J. Diez, "Arterial stiffness and extracellular matrix," Advances in Cardiology, vol. 44, pp. 76-95, 2007.

[171] M. Hogan, A. Cerami, and R. Bucala, "Advanced glycosylation endproducts block the antiproliferative effect of nitric oxide. Role in the vascular and renal complications of diabetes mellitus," Journal of Clinical Investigation, vol. 90, no. 3, pp. 1110-1115, 1992.

[172] S. D. Funk, A. Yurdagul, J. M. Green, K. A. Jhaveri, M. A. Schwartz, and A. W. Orr, "Matrix-specific protein kinase a signaling regulates $\mathrm{p} 21$-activated kinase activation by flow in endothelial cells," Circulation Research, vol. 106, no. 8, pp. 1394-1403, 2010.

[173] C. S. Haitoglou, E. C. Tsilibary, M. Brownlee, and A. S. Charonis, "Altered cellular interactions between endothelial cells and nonenzymatically glucosylated laminin/type IV collagen," Journal of Biological Chemistry, vol. 267, no. 18, pp. 12404-12407, 1992.
[174] A. S. Charonis, L. A. Reger, J. E. Dege et al., "Laminin alterations after in vitro nonenzymatic glycosylation," Diabetes, vol. 39, no. 7, pp. 807-814, 1990.

[175] H. Yamawaki, K. Saito, M. Okada, and Y. Hara, "Methylglyoxal mediates vascular inflammation via JNK and p38 in human endothelial cells," American Journal of PhysiologyCell Physiology, vol. 295, no. 6, pp. C1510-C1517, 2008.

[176] G. Tang, Y. Minemoto, B. Dibling et al., "Inhibition of JNK activation through NF- $\kappa$ B target genes," Nature, vol. 414, no. 6861, pp. 313-317, 2001.

[177] W. H. Chan and H. J. Wu, "Methylglyoxal and high glucose co-treatment induces apoptosis or necrosis in human umbilical vein endothelial cells," Journal of Cellular Biochemistry, vol. 103, no. 4, pp. 1144-1157, 2008.

[178] N. Younis, R. Sharma, H. Soran, V. Charlton-Menys, M. Elseweidy, and P. N. Durrington, "Glycation as an atherogenic modification of LDL," Current Opinion in Lipidology, vol. 19, no. 4, pp. 378-384, 2008.

[179] L. Toma, C. S. Stancu, G. M. Botez, A. V. Sima, and M. Simionescu, "Irreversibly glycated LDL induce oxidative and inflammatory state in human endothelial cells; added effect of high glucose," Biochemical and Biophysical Research Communications, vol. 390, no. 3, pp. 877-882, 2009.

[180] G. M. Ma, A. J. Halayko, G. L. Stelmack et al., "Effects of oxidized and glycated low-density lipoproteins on transcription and secretion of plasminogen activator inhibitor- 1 in vascular endothelial cells," Cardiovascular Pathology, vol. 15, no. 1, pp. 3-10, 2006.

[181] G. V. Sangle, S. K. R. Chowdhury, X. Xie, G. L. Stelmack, A. J. Halayko, and G. X. Shen, "Impairment of mitochondrial respiratory chain activity in aortic endothelial cells induced by glycated low-density lipoprotein," Free Radical Biology and Medicine, vol. 48, no. 6, pp. 781-790, 2010.

[182] Y. Dong, Y. Wu, M. Wu et al., "Activation of protease calpain by oxidized and glycated LDL increases the degradation of endothelial nitric oxide synthase," Journal of Cellular and Molecular Medicine, vol. 13, no. 9, pp. 2899-2910, 2009.

[183] A. M. Watson, A. Soro-Paavonen, K. Sheehy et al., "Delayed intervention with AGE inhibitors attenuates the progression of diabetes-accelerated atherosclerosis in diabetic apolipoprotein E knockout mice," Diabetologia, vol. 54, no. 3, pp. 681-689, 2011.

[184] J. M. Forbes, L. T. L. Yee, V. Thallas et al., "Advanced glycation end product-interventions reduce diabetes-accelerated atherosclerosis," Diabetes, vol. 53, no. 7, pp. 1813-1823, 2004.

[185] D. A. Kass, E. P. Shapiro, M. Kawaguchi et al., "Improved arterial compliance by a novel advanced glycation endproduct crosslink breaker," Circulation, vol. 104, no. 13, pp. 1464-1470, 2001.

[186] M. A. Zieman, "A heart that keeps on beating," Behavioral Healthcare, vol. 27, no. 9, pp. 22-26, 2007.

[187] O. Brouwers, P. M. Niessen, I. Ferreira et al., "Overexpression of glyoxalase-I reduces hyperglycemiainduced levels of advanced glycation end products and oxidative stress in diabetic rats," Journal of Biological Chemistry, vol. 286, no. 2, pp. 1374-1380, 2011.

[188] L. Engelen, I. Ferreira, O. Brouwers et al., "Polymorphisms in glyoxalase 1 gene are not associated with vascular complications: the Hoorn and CoDAM studies," Journal of Hypertension, vol. 27, no. 7, pp. 1399-1403, 2009.

[189] J. C. Wu, X. H. Li, Y. D. Peng, J. B. Wang, J. F. Tang, and Y. F. Wang, "Association of two glyoxalase 1gene polymorphisms 
with nephropathy and retinopathy in type 2 diabetes," Journal of Endocrinological Investigation, vol. 34, no. 10, pp. e343-e348, 2011.

[190] L. Park, K. G. Raman, K. J. Lee et al., "Suppression of accelerated diabetic atherosclerosis by the soluble receptor for advanced glycation endproducts," Nature Medicine, vol. 4, no. 9, pp. 1025-1031, 1998.

[191] L. G. Bucciarelli, T. Wendt, W. Qu et al., "RAGE blockade stabilizes established atherosclerosis in diabetic apolipoprotein E-null mice," Circulation, vol. 106, no. 22, pp. 2827-2835, 2002.

[192] E. Harja, D. X. Bu, B. I. Hudson et al., "Vascular and inflammatory stresses mediate atherosclerosis via RAGE and its ligands in apoE-/- mice," Journal of Clinical Investigation, vol. 118, no. 1, pp. 183-194, 2008.

[193] N. A. Calcutt, M. E. Cooper, T. S. Kern, and A. M. Schmidt, "Therapies for hyperglycaemia-induced diabetic complications: from animal models to clinical trials," Nature Reviews Drug Discovery, vol. 8, no. 5, pp. 417-429, 2009.

[194] R. G. Gonzalez, P. Barnett, and J. Aguayo, "Direct measurement of polyol pathway activity in the ocular lens," Diabetes, vol. 33, no. 2, pp. 196-199, 1984.

[195] A. D. Morrison, R. S. Clements Jr, S. B. Travis, F. Oski, and A. I. Winegrad, "Glucose utilization by the polyol pathway in human erythrocytes," Biochemical and Biophysical Research Communications, vol. 40, no. 1, pp. 199-205, 1970.

[196] S. K. Srivastava, K. V. Ramana, and A. Bhatnagar, "Role of aldose reductase and oxidative damage in diabetes and the consequent potential for therapeutic options," Endocrine Reviews, vol. 26, no. 3, pp. 380-392, 2005.

[197] R. Ramasamy and I. J. Goldberg, "Aldose reductase and cardiovascular diseases, creating human-like diabetic complications in an experimental model," Circulation Research, vol. 106, no. 9, pp. 1449-1458, 2010.

[198] J. H. Kinoshita, D. Dvornik, M. Kramil, and K. H. Gabbay, "The effect of an aldose reductase inhibitor on the galactoseexposed rabbit lens," Biochimica et Biophysica Acta, vol. 158, no. 3, pp. 472-475, 1968.

[199] S. D. Varma and J. H. Kinoshita, "Inhibition of lens aldose reductase by flavonoids: their possible role in the prevention of diabetic cataracts," Biochemical Pharmacology, vol. 25, no. 22, pp. 2505-2513, 1976.

[200] S. D. Varma, A. Mizuno, and J. H. Kinoshita, "Diabetic cataracts and flavonoids," Science, vol. 195, no. 4274, pp. 205206, 1977.

[201] S. K. Srivastava and N. H. Ansari, "Prevention of sugar-induced cataractogenesis in rats by butylated hydroxytoluene," Diabetes, vol. 37, no. 11, pp. 1505-1508, 1988.

[202] N. H. Ansari and S. K. Srivastava, "Allopurinol promotes and butylated hydroxy toluene prevents sugar-induced cataractogenesis," Biochemical and Biophysical Research Communications, vol. 168, no. 3, pp. 939-943, 1990.

[203] N. H. Ansari, A. Bhatnagar, E. Fulep, P. Khanna, and S. K. Srivastava, "Trolox protects hyperglycemia-induced cataractogenesis in cultured rat lens," Research Communications in Chemical Pathology and Pharmacology, vol. 84, no. 1, pp. 93104, 1994.

[204] T. S. Kern and R. L. Engerman, "Immunohistochemical distribution of aldose reductase," Histochemical Journal, vol. 14, no. 3, pp. 507-515, 1982.

[205] H. Omi, N. Okayama, M. Shimizu et al., "Participation of high glucose concentrations in neutrophil adhesion and surface expression of adhesion molecules on cultured human endothelial cells: effect of antidiabetic medicines," Journal of Diabetes and its Complications, vol. 16, no. 3, pp. 201-208, 2002.

[206] K. V. Ramana, A. Bhatnagar, and S. K. Srivastava, "Inhibition of aldose reductase attenuates TNF- $\alpha$-induced expression of adhesion molecules in endothelial cells," FASEB Journal, vol. 18, no. 11, pp. 1209-1218, 2004.

[207] S. Srivastava, M. Spite, J. O. Trent, M. B. West, Y. Ahmed, and A. Bhatnagar, "Aldose reductase-catalyzed reduction of aldehyde phospholipids," Journal of Biological Chemistry, vol. 279, no. 51, pp. 53395-53406, 2004.

[208] K. V. Ramana, B. L. Dixit, S. Srivastava, G. K. Balendiran, S. K. Srivastava, and A. Bhatnagar, "Selective recognition of glutathiolated aldehydes by aldose reductase," Biochemistry, vol. 39, no. 40, pp. 12172-12180, 2000.

[209] K. V. Ramana and S. K. Srivastava, "Aldose reductase: a novel therapeutic target for inflammatory pathologies," International Journal of Biochemistry and Cell Biology, vol. 42, no. 1, pp. 17-20, 2010.

[210] S. Srivastava, E. Vladykovskaya, O. A. Barski et al., "Aldose reductase protects against early atherosclerotic lesion formation in apolipoprotein E-null mice," Circulation Research, vol. 105, no. 8, pp. 793-802, 2009.

[211] S. Vedantham, H. Noh, and R. Ananthakrishnan, "Human aldose reductase expression accelerates atherosclerosis in diabetic apolipoprotein E-/- mice," Arteriosclerosis, Thrombosis, and Vascular Biology, vol. 31, no. 8, pp. 1805-1813, 2011.

[212] R. K. Vikramadithyan, Y. Hu, H. L. Noh et al., "Human aldose reductase expression accelerates diabetic atherosclerosis in transgenic mice," Journal of Clinical Investigation, vol. 115, no. 9, pp. 2434-2443, 2005.

[213] A. G. Rajapakse, X. F. Ming, J. M. Carvas, and Z. Yang, “The hexosamine biosynthesis inhibitor azaserine prevents endothelial inflammation and dysfunction under hyperglycemic condition through antioxidant effects," American Journal of Physiology-Heart and Circulatory Physiology, vol. 296, no. 3, pp. H815-H822, 2009.

[214] H. Goldberg, C. Whiteside, and I. G. Fantus, "O-linked $\beta-\mathrm{N}-$ acetylglucosa mine supports p38 MAPK activation by high glucose in glomerular mesangial cells," American Journal of Physiology'Endocrinology and Metabolism, vol. 301, no. 4, pp. E713-E726, 2011.

[215] R. S. Haltiwanger, M. A. Blomberg, and G. W. Hart, "Glycosylation of nuclear and cytoplasmic proteins. Purification and characterization of a uridine diphospho-N-acetylglucosamine: polypeptide $\beta$-N- acetylglucosaminyltransferase," Journal of Biological Chemistry, vol. 267, no. 13, pp. 9005-9013, 1992.

[216] R. S. Haltiwanger, G. D. Holt, and G. W. Hart, "Enzymatic addition of O-GlcNAc to nuclear and cytoplasmic proteins. Identification of a uridine diphospho- $\mathrm{N}$-acetylglucosamine: peptide $\beta$-N-acetylglucosaminyltransferase," Journal of Biological Chemistry, vol. 265, no. 5, pp. 2563-2568, 1990.

[217] B. Laczy, B. G. Hill, K. Wang et al., "Protein O-GlcNAcylation: a new signaling paradigm for the cardiovascular system," American Journal of Physiology-Heart and Circulatory Physiology, vol. 296, no. 1, pp. H13-H28, 2009.

[218] B. Laczy, S. A. Marsh, C. A. Brocks, I. Wittmann, and J. C. Chatham, "Inhibition of O-GlcNAcase in perfused rat hearts by NAG-thiazolines at the time of reperfusion is cardioprotective in an O-GlcNAc-dependent manner," American Journal of Physiology-Heart and Circulatory Physiology, vol. 299, no. 5, pp. H1715-H1727, 2010. 
[219] T. Wu, H. Zhou, Z. Jin et al., "Cardioprotection of salidroside from ischemia/reperfusion injury by increasing $\mathrm{N}$ acetylglucosamine linkage to cellular proteins," European Journal of Pharmacology, vol. 613, no. 1-3, pp. 93-99, 2009.

[220] Y. Ju, J. Hua, K. Sakamoto, H. Ogawa, and I. Nagaoka, "Modulation of TNF- $\alpha$-induced endothelial cell activation by glucosamine, a naturally occurring amino monosaccharide," International Journal of Molecular Medicine, vol. 22, no. 6, pp. 809-815, 2008.

[221] Y. Ju, J. Hua, K. Sakamoto, H. Ogawa, and I. Nagaoka, “Glucosamine, a naturally occurring amino monosaccharide modulates LL-37-induced endothelial cell activation," International Journal of Molecular Medicine, vol. 22, no. 5, pp. 657-662, 2008.

[222] B. Musicki, M. F. Kramer, R. E. Becker, and A. L. Burnett, "Inactivation of phosphorylated endothelial nitric oxide synthase (Ser-1177) by O-GlcNAc in diabetes-associated erectile dysfunction," Proceedings of the National Academy of Sciences of the United States of America, vol. 102, no. 33, pp. 11870-11875, 2005.

[223] M. Federici, R. Menghini, A. Mauriello et al., "Insulindependent activation of endothelial nitric oxide synthase is impaired by O-linked glycosylation modification of signaling proteins in human coronary endothelial cells," Circulation, vol. 106, no. 4, pp. 466-472, 2002.

[224] X. L. Du, D. Edelstein, L. Rossetti et al., "Hyperglycemiainduced mitochondrial superoxide overproduction activates the hexosamine pathway and induces plasminogen activator inhibitor-1 expression by increasing Sp1 glycosylation," Proceedings of the National Academy of Sciences of the United States of America, vol. 97, no. 22, pp. 12222-12226, 2000.

[225] Y. Q. Chen, M. Su, R. R. Walia, Q. Hao, J. W. Covington, and D. E. Vaughan, "Sp1 sites mediate activation of the plasminogen activator inhibitor-1 promoter by glucose in vascular smooth muscle cells," Journal of Biological Chemistry, vol. 273, no. 14, pp. 8225-8231, 1998.

[226] G. D. Holt and G. W. Hart, "The subcellular distribution of terminal $\mathrm{N}$-acetylglucosamine moieties. Localization of a novel protein-saccharidie linkage, O-linked GlcNAc," Journal of Biological Chemistry, vol. 261, no. 17, pp. 8049-8057, 1986.

[227] P. J. Oates, "Aldose reductase, still a compelling target for diabetic neuropathy," Current Drug Targets, vol. 9, no. 1, pp. 14-36, 2008.

[228] S. K. Srivastava, U. C. S. Yadav, A. B. M. Reddy et al., "Aldose reductase inhibition suppresses oxidative stress-induced inflammatory disorders," Chemico-Biological Interactions, vol. 191, no. 1-3, pp. 330-338, 2011.

[229] P. Alexiou, K. Pegklidou, M. Chatzopoulou, I. Nicolaou, and V. J. Demopoulos, "Aldose reductase enzyme and its implication to major health problems of the $21^{\text {st }}$ century," Current Medicinal Chemistry, vol. 16, no. 6, pp. 734-752, 2009.

[230] P. Geraldes and G. L. King, "Activation of protein kinase C isoforms and its impact on diabetic complications," Circulation Research, vol. 106, no. 8, pp. 1319-1331, 2010.

[231] M. E. Reyland, "Protein kinase C isoforms: multi-functional regulators of cell life and death," Frontiers in Bioscience, vol. 14, no. 6, pp. 2386-2399, 2009.

[232] X. Du, T. Matsumura, D. Edelstein et al., "Inhibition of GAPDH activity by poly(ADP-ribose) polymerase activates three major pathways of hyperglycemic damage in endothelial cells," Journal of Clinical Investigation, vol. 112, no. 7, pp. 1049-1057, 2003.
[233] V. Thallas-Bonke, S. R. Thorpe, M. T. Coughlan et al., "Inhibition of NADPH oxidase prevents advanced glycation end product-mediated damage in diabetic nephropathy through a protein kinase C- $\alpha$-dependent pathway," Diabetes, vol. 57, no. 2, pp. 460-469, 2008.

[234] I. Fleming, B. Fisslthaler, S. Dimmeler, B. E. Kemp, and R. Busse, "Phosphorylation of $\mathrm{Thr}^{495}$ regulates $\mathrm{Ca}^{2+}$ / calmodulin-dependent endothelial nitric oxide synthase activity," Circulation research, vol. 88, no. 11, pp. E68-E75, 2001.

[235] K. I. Hirata, R. Kuroda, T. Sakoda et al., "Inhibition of endothelial nitric oxide synthase activity by protein kinase C," Hypertension, vol. 25, no. 2, pp. 180-185, 1995.

[236] X. Jiang, F. Yang, H. Tan et al., "Hyperhomocystinemia impairs endothelial function and eNOS activity via PKC activation," Arteriosclerosis, Thrombosis, and Vascular Biology, vol. 25, no. 12, pp. 2515-2521, 2005.

[237] B. J. Michell, Z. P. Chen, T. Tiganis et al., "Coordinated control of endothelial nitric-oxide synthase phosphorylation by protein kinase $\mathrm{C}$ and the cAMP-dependent protein pinase," Journal of Biological Chemistry, vol. 276, no. 21, pp. 17625-17628, 2001.

[238] P. Nigro, J. I. Abe, C. H. Woo et al., "PKC $\zeta$ decreases eNOS protein stability via inhibitory phosphorylation of ERK5," Blood, vol. 116, no. 11, pp. 1971-1979, 2010.

[239] R. Magid and P. F. Davies, "Endothelial protein kinase C isoform identity and differential activity of $\mathrm{PKC} \zeta$ in an athero-susceptible region of porcine aorta," Circulation Research, vol. 97, no. 5, pp. 443-449, 2005.

[240] I. Fleming, A. Mohamed, J. Galle et al., "Oxidized low-density lipoprotein increases superoxide production by endothelial nitric oxide synthase by inhibiting $\mathrm{PKC} \alpha$," Cardiovascular Research, vol. 65, no. 4, pp. 897-906, 2005.

[241] C. Partovian, Z. Zhuang, K. Moodie et al., "PKC $\alpha$ activates eNOS and increases arterial blood flow in vivo," Circulation Research, vol. 97, no. 5, pp. 482-487, 2005.

[242] N. S. Harhaj, E. A. Felinski, E. B. Wolpert et al., "VEGF activation of protein kinase $\mathrm{C}$ stimulates occludin phosphorylation and contributes to endothelial permeability," Investigative Ophthalmology and Visual Science, vol. 47, no. 11, pp. 51065115, 2006.

[243] J. J. Lynch, T. J. Ferro, F. A. Blumenstock, A. M. Brockenauer, and A. B. Malik, "Increased endothelial albumin permeability mediated by protein kinase C activation," Journal of Clinical Investigation, vol. 85, no. 6, pp. 1991-1998, 1990.

[244] B. Williams, B. Gallacher, H. Patel, and C. Orme, "Glucoseinduced protein kinase $\mathrm{C}$ activation regulates vascular permeability factor mRNA expression and peptide production by human vascular smooth muscle cells in vitro," Diabetes, vol. 46, no. 9, pp. 1497-1503, 1997.

[245] J. Y. Park, N. Takahara, A. Gabriele et al., "Induction of endothelin-1 expression by glucose an effect of protein kinase C activation," Diabetes, vol. 49, no. 7, pp. 1239-1248, 2000.

[246] R. D. Minshall, E. E Vandenbroucke, M. Holinstat et al., "Role of protein kinase Czeta in thrombin-induced RhoA activation and inter-endothelial gap formation of human dermal microvessel endothelial cell monolayers," Microvascular Research, vol. 80, no. 2, pp. 240-249, 2010.

[247] A. Rahman, M. Bando, J. Kefer, K. N. Anwar, and A. B. Malik, "Protein kinase C-activated oxidant generation in endothelial cells signals intercellular adhesion molecule-1 gene transcription," Molecular Pharmacology, vol. 55, no. 3, pp. 575-583, 1999. 
[248] J. I. Abe, "Role of PKCs and NF- $\kappa$ B activation in myocardial inflammation: enemy or ally?" Journal of Molecular and Cellular Cardiology, vol. 43, no. 4, pp. 404-408, 2007.

[249] D. T. Bolick, S. Srinivasan, A. Whetzel et al., "12/15 lipoxygenase mediates monocyte adhesion to aortic endothelium in apolipoprotein E-deficient mice through activation of RhoA and NF- $\kappa \mathrm{B}$," Arteriosclerosis, Thrombosis, and Vascular Biology, vol. 26, no. 6, pp. 1260-1266, 2006.

[250] A. Kawakami, M. Aikawa, N. Nitta et al., "Apolipoprotein CIII-induced THP-1 cell adhesion to endothelial cells involves pertussis toxin-sensitive $G$ protein- and protein kinase C $\alpha$-mediated nuclear factor- $\kappa \mathrm{B}$ activation," Arteriosclerosis, Thrombosis, and Vascular Biology, vol. 27, no. 1, pp. 219-225, 2007.

[251] T. Minami, R. M. Abid, J. Zhang, G. King, T. Kodama, and W. C. Aird, "Thrombin stimulation of vascular adhesion molecule-1 in endothelial cells is mediated by protein kinase C (PKC) $-\delta$-NF- $\kappa \mathrm{B}$ and PKC- $\zeta$-GATA signaling pathways," Journal of Biological Chemistry, vol. 278, no. 9, pp. 69766984, 2003.

[252] A. Rahman, K. N. Anwar, S. Uddin et al., "Protein kinase C- $\delta$ regulates thrombin-induced ICAM-1 gene expression in endothelial cells via activation of p38 mitogen-activated protein kinase," Molecular and Cellular Biology, vol. 21, no. 16, pp. 5554-5565, 2001.

[253] A. Rahman, K. N. Anwar, and A. B. Malik, "Protein kinase $\mathrm{C}-\zeta$ mediates TNF- $\alpha$-induced ICAM-1 gene transcription in endothelial cells," American Journal of Physiology-Cell Physiology, vol. 279, no. 4, pp. C906-C914, 2000.

[254] U. Chakravarthy, R. G. Hayes, A. W. Stitt, E. McAuley, and D. B. Archer, "Constitutive nitric oxide synthase expression in retinal vascular endothelial cells is suppressed by high glucose and advanced glycation end products," Diabetes, vol. 47, no. 6, pp. 945-952, 1998.

[255] F. Cosentino, M. Eto, P. de Paolis et al., "High glucose causes upregulation of cyclooxygenase-2 and alters prostanoid profile in human endothelial cells: role of protein kinase $\mathrm{C}$ and reactive oxygen species," Circulation, vol. 107, no. 7, pp. 1017-1023, 2003.

[256] T. Inoguchi, P. Li, F. Umeda et al., "High glucose level and free fatty acid stimulate reactive oxygen species production through protein kinase C-dependent activation of $\mathrm{NAD}(\mathrm{P}) \mathrm{H}$ oxidase in cultured vascular cells," Diabetes, vol. 49, no. 11, pp. 1939-1945, 2000.

[257] A. Hempel, C. Maasch, U. Heintze et al., "High glucose concentrations increase endothelial cell permeability via activation of protein kinase C $\alpha$," Circulation Research, vol. 81, no. 3, pp. 363-371, 1997.

[258] B. A. Wolf, J. R. Williamson, R. A. Easom, K. Chang, W. R. Sherman, and J. Turk, "Diacylglycerol accumulation and microvascular abnormalities induced by elevated glucose levels," Journal of Clinical Investigation, vol. 87, no. 1, pp. 3138, 1991.

[259] N. Gaudreault, R. M. Perrin, M. Guo et al., "Counter regulatory effects of $\mathrm{PKC} \beta \mathrm{II}$ and $\mathrm{PKC} \delta$ on coronary endothelial permeability," Arteriosclerosis, Thrombosis, and Vascular Biology, vol. 28, no. 8, pp. 1527-1533, 2008.

[260] G. M. Pieper and U. H. Riaz, "Activation of nuclear factor- $\kappa$ B in cultured endothelial cells by increased glucose concentration: prevention by calphostin C," Journal of Cardiovascular Pharmacology, vol. 30, no. 4, pp. 528-532, 1997.
[261] Y. Xu, S. Wang, L. Feng, Q. Zhu, P. Xiang, and B. He, "Blockade of PKC- $\beta$ protects HUVEC from advanced glycation end products induced inflammation," International Immunopharmacology, vol. 10, no. 12, pp. 1552-1559, 2010.

[262] A. Kouroedov, M. Eto, H. Joch, M. Volpe, T. F. Lüscher, and F. Cosentino, "Selective inhibition of protein kinase $\mathrm{C} \beta 2$ prevents acute effects of high glucose on vascular cell adhesion molecule-1 expression in human endothelial cells," Circulation, vol. 110, no. 1, pp. 91-96, 2004.

[263] L. Quagliaro, L. Piconi, R. Assaloni, L. Martinelli, E. Motz, and A. Ceriello, "Intermittent high glucose enhances apoptosis related to oxidative stress in human umbilical vein endothelial cells: the role of protein kinase $\mathrm{C}$ and $\mathrm{NAD}(\mathrm{P}) \mathrm{H}-$ oxidase activation," Diabetes, vol. 52, no. 11, pp. 2795-2804, 2003.

[264] T. Inoguchi, R. Battan, E. Handler, J. R. Sportsman, W. Heath, and G. L. King, "Preferential elevation of protein kinase C isoform $\beta \mathrm{II}$ and diacylglycerol levels in the aorta and heart of diabetic rats: differential reversibility to glycemic control by islet cell transplantation," Proceedings of the National Academy of Sciences of the United States of America, vol. 89, no. 22, pp. 11059-11063, 1992.

[265] N. Kang, G. Alexander, J. K. Park et al., "Differential expression of protein kinase $\mathrm{C}$ isoforms in streptozotocininduced diabetic rats," Kidney International, vol. 56, no. 5, pp. 1737-1750, 1999.

[266] T. Shiba, T. Inoguchi, J. R. Sportsman, W. F. Heath, S. Bursell, and G. L. King, "Correlation of diacylglycerol level and protein kinase C activity in rat retina to retinal circulation," American Journal of Physiology, vol. 265, no. 5, part 1, pp. E783-E793, 1993.

[267] N. das Evcimen and G. L. King, "The role of protein kinase C activation and the vascular complications of diabetes," Pharmacological Research, vol. 55, no. 6, pp. 498-510, 2007.

[268] G. Booth, T. J. Stalker, A. M. Lefer, and R. Scalia, "Mechanisms of amelioration of glucose-induced endothelial dysfunction following inhibition of protein kinase C in vivo," Diabetes, vol. 51, no. 5, pp. 1556-1564, 2002.

[269] E. Harja, S. C. Jong, Y. Lu et al., "Mice deficient in PKC $\beta$ and apolipoprotein E display decreased atherosclerosis," FASEB Journal, vol. 23, no. 4, pp. 1081-1091, 2009.

[270] H. Ishii, M. R. Jirousek, D. Koya et al., "Amelioration of vascular dysfunctions in diabetic rats by an oral PKC $\beta$ inhibitor," Science, vol. 272, no. 5262, pp. 728-731, 1996.

[271] M. R. Nangle, M. A. Cotter, and N. E. Cameron, "Protein kinase $C \beta$ inhibition and aorta and corpus cavernosum function in streptozotocin-diabetic mice," European Journal of Pharmacology, vol. 475, no. 1-3, pp. 99-106, 2003.

[272] J. A. Beckman, A. B. Goldfine, M. B. Gordon, L. A. Garrett, and M. A. Creager, "Inhibition of protein kinase $\mathrm{C} \beta$ prevents impaired endothelium-dependent vasodilation caused by hyperglycemia in humans," Circulation Research, vol. 90, no. 1, pp. 107-111, 2002.

[273] N. N. Mehta, M. Sheetz, K. Price et al., "Selective PKC $\beta$ inhibition with ruboxistaurin and endothelial function in type-2 diabetes mellitus," Cardiovascular Drugs and Therapy, vol. 23, no. 1, pp. 17-24, 2009. 


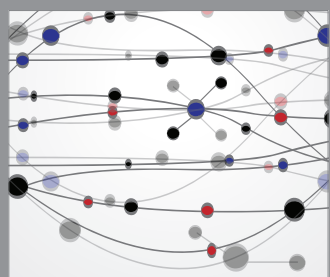

The Scientific World Journal
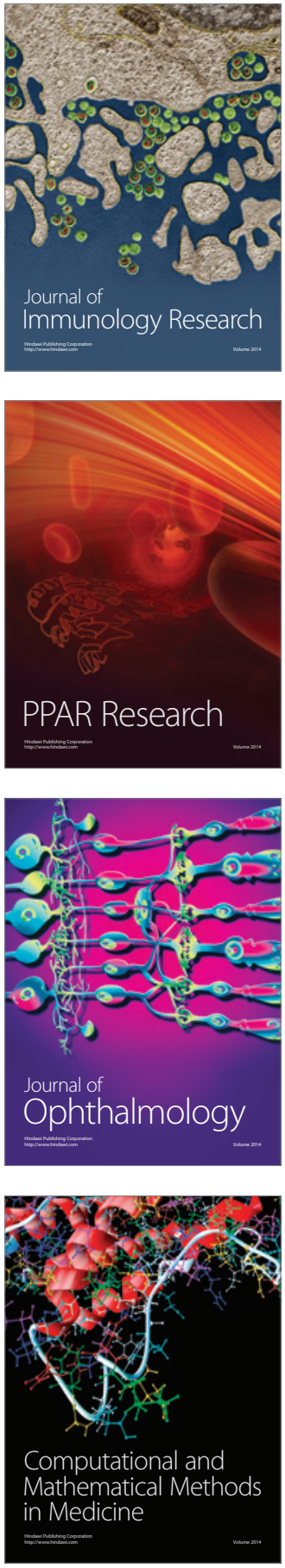

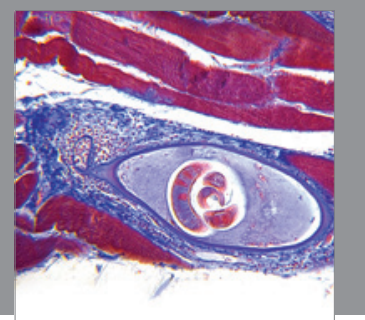

Gastroenterology

Research and Practice
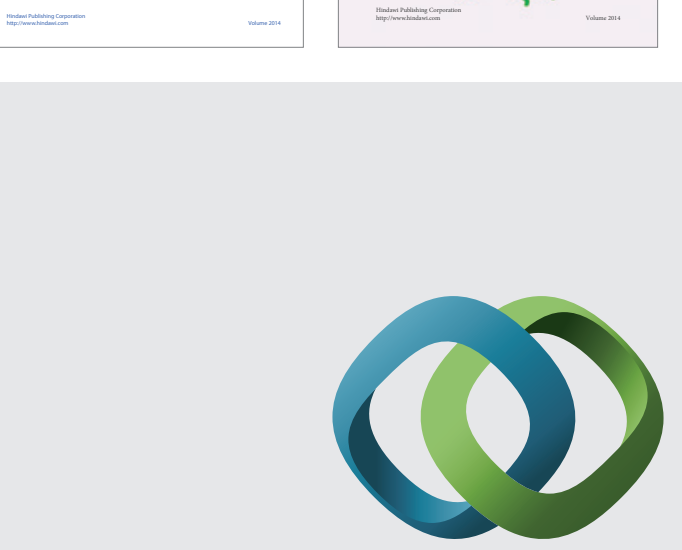

\section{Hindawi}

Submit your manuscripts at

http://www.hindawi.com
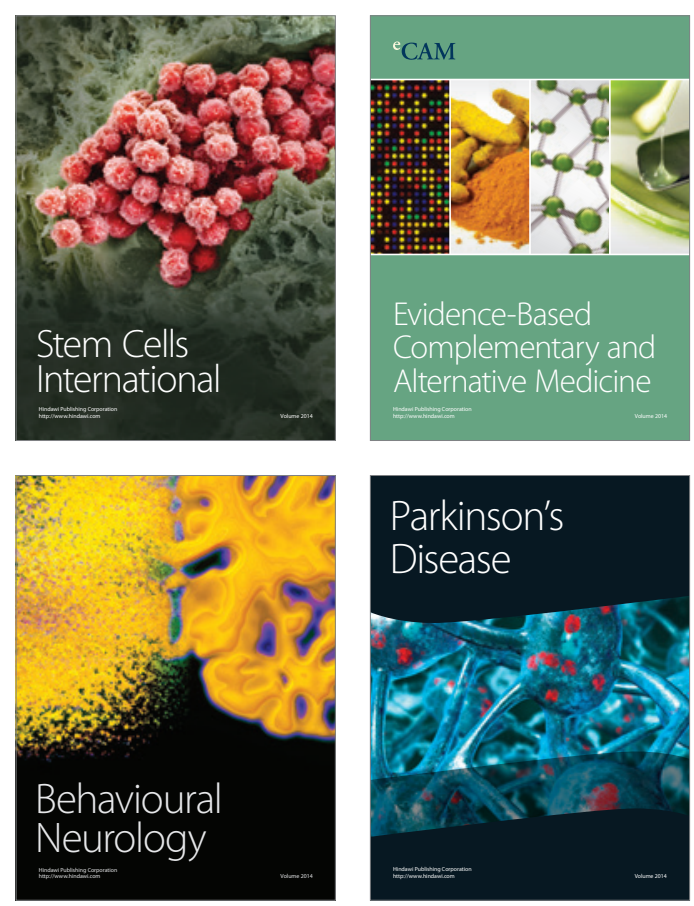

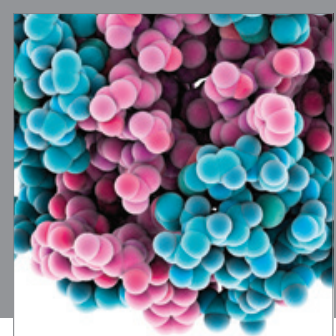

Journal of
Diabetes Research

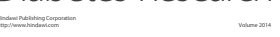

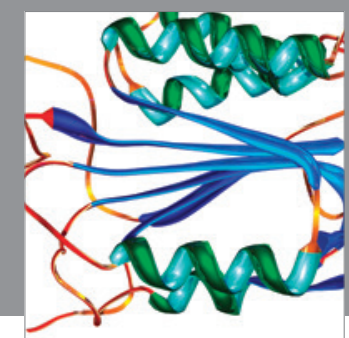

Disease Markers
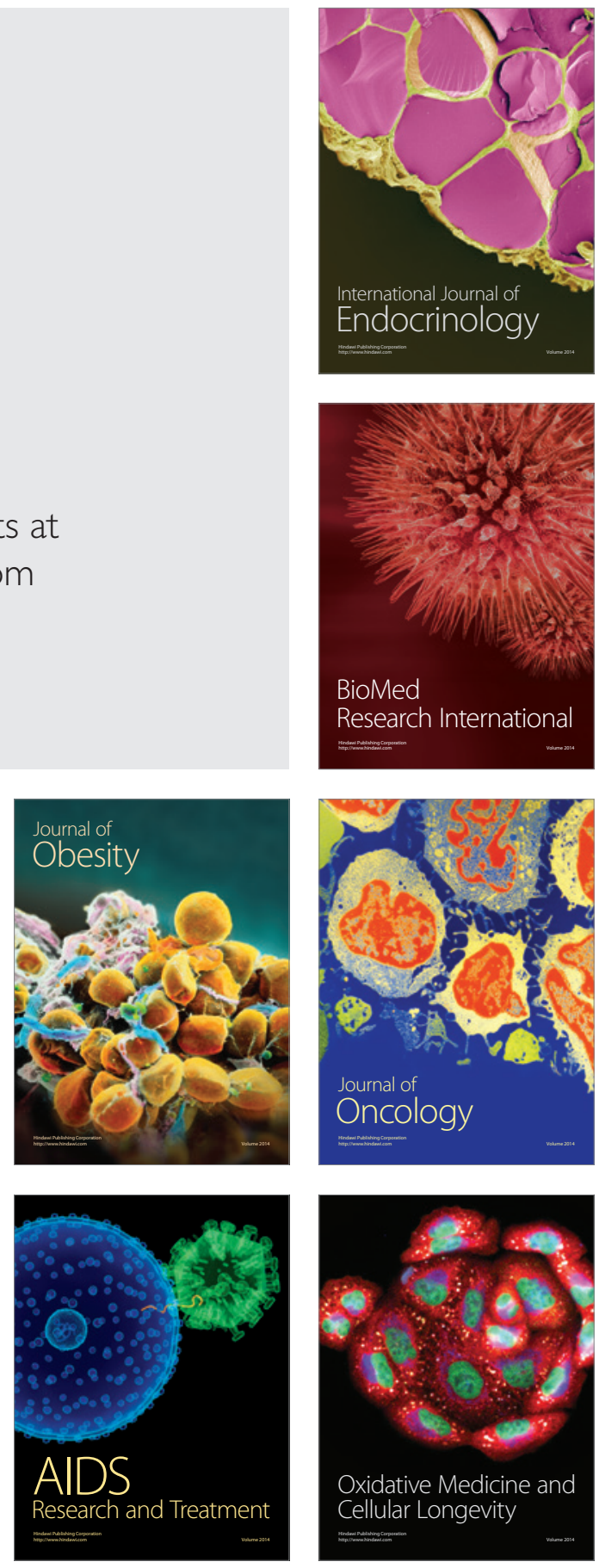